\title{
$100 \%$ Fruit juice intake and cardiovascular risk: a systematic review and meta-analysis of prospective and randomised controlled studies
}

\author{
Lanfranco D'Elia ${ }^{1} \mathbb{D} \cdot$ Monica Dinu ${ }^{2} \cdot$ Francesco Sofi $^{2} \cdot$ Massimo Volpe $^{3,4} \cdot$ Pasquale Strazzullo $^{1}$ on behalf of The SINU \\ Working Group, Endorsed by SIPREC
}

Received: 27 May 2020 / Accepted: 19 October 2020 / Published online: 4 November 2020

(c) The Author(s) 2020

\begin{abstract}
Purpose The relationship between $100 \%$ fruit juice $(100 \% \mathrm{FJ})$ consumption and cardiovascular risk is object of debate: indeed, recently published investigations provided new but discrepant evidence on this important question and International dietary guidelines are not in agreement on recommendations about fruit juice consumption. Therefore, we performed a meta-analysis of the prospective studies and the randomised controlled trials (RCTs) that explored the relationship between $100 \% \mathrm{FJ}$ intake, cardiovascular risk profile and risk of cardiovascular events.

Methods We performed a systematic search of publications up to August 2019. Summary relative risks and exploration of linearity of the association were estimated for prospective studies and summary mean differences (MDs) calculated for RCTs. Results A total of 21 prospective studies and 35 RCTs met the inclusion criteria. Dose-response analysis detected a significant inverse association between low-moderate $100 \% \mathrm{FJ}$ consumption and risk of stroke (up to $200 \mathrm{ml} /$ day) or total CV events (up to $170 \mathrm{ml} /$ day) compared with no consumption, with a non-linear relationship ( $p$ for non-linearity $<0.05$ ). No significant association was found for coronary heart disease and diabetes risk. In RCTs, a favorable and significant effect of $100 \% \mathrm{FJ}$ intake was detected on blood pressure (systolic, MD: $-3.14 \mathrm{mmHg}$; diastolic, $\mathrm{MD}$ : $-1.68 \mathrm{mmHg}$ ), arterial compliance (carotid-femoral pulse wave velocity, $-0.38 \mathrm{~m} / \mathrm{s}$ ) and endothelial function (flow-mediated dilation, $2.10 \%$ ). Neutral effects were found on body weight, blood lipids and glucose metabolism.

Conclusions The results of these analyses indicate that $100 \% \mathrm{FJ}$ consumption is not associated with higher CV risk. A nonlinear inverse dose-response relationship occurs between $100 \% \mathrm{FJ}$ consumption and $\mathrm{CV}$ disease, in particular for risk of stroke, probably mediated by the decrease in blood pressure.
\end{abstract}

Trial registration PROSPERO registration number (CRD42019135577).

Keywords Fruit juice $\cdot$ Cardiovascular disease $\cdot$ Cardiovascular risk factors $\cdot$ Blood pressure $\cdot$ Meta-analysis

The members of "The SINU Working Group (Italian Society of Human Nutrition (SINU), 20126, Milan, Italy)" are listed in acknowledgement section.

The paper was endorsed by SIPREC (Italian Society for the Cardiovascular Prevention (SIPREC), 00197, Rome, Italy)

Electronic supplementary material The online version of this article (https://doi.org/10.1007/s00394-020-02426-7) contains supplementary material, which is available to authorized users.

Lanfranco D’Elia

lanfranco.delia@unina.it

Extended author information available on the last page of the article

\section{Introduction}

The pivotal role of fresh fruits and vegetables in a healthy diet is universally acknowledged and increased consumption of these foods is recommended by all the international guidelines for prevention of cardiovascular (CV) disease [1, 2]. On the other hand, the role of processed fruits, and in particular of $100 \%$ fruit juice $(100 \% \mathrm{FJ})$, is object of debate because of its reduced nutritional value compared to fresh fruit mainly due to the generally lower fibre content and to the higher caloric density. However, $100 \%$ FJ provides substantial amounts of micronutrients and bioactive substances, among which polyphenols, minerals and vitamins. These nutrients may reduce oxidative stress and improve inflammatory markers, glucose metabolism [3, 4] and endothelial 
function [5], while inhibiting platelet aggregation [6]. For these reasons [7, 8], several studies were performed to analyse their possible influence on $\mathrm{CV}$ disorders, a major cause of death worldwide $[9,10]$. While some epidemiological studies suggested that consumption of fruit drinks may have beneficial effects on CV risk [11-14], others provided contrasting evidence [15-17]. Unfortunately, most studies were not able to specify the exact properties of the fruit drinks consumed, i.e., whether $100 \% \mathrm{FJ}$ or unspecified fruit drinks, and none explored the possibility of non-linear associations. In addition to prospective observational studies, many intervention trials were carried out to investigate the potential effect of fruit juice intake (mostly $100 \% \mathrm{FJ}$ ) on $\mathrm{CV}$ risk profile and many of them have been the object of various systematic reviews. One of these suggested a beneficial effect on diastolic blood pressure (BP) but, including several studies classified as low quality [18]. Other meta-analyses were limited to a single type of fruit or combined the effects of $100 \% \mathrm{FJ}$ and fruit extracts $[19,20]$ or included of nonrandomised controlled trials [21,22].

The aim of the present study was thus to perform a comprehensive systematic review and subsequent meta-analysis of the prospective studies and the randomised controlled trials (RCTs) that explored the relationship between $100 \% \mathrm{FJ}$ intake, $\mathrm{CV}$ risk profile and risk of $\mathrm{CV}$ events, aiming at clarifying the shape and strength of the dose-response relationship for these associations, if at all possible. As for prospective investigations the majority did not specify the type of fruit drink consumed by participants, we performed separate analyses of the few studies dealing with $100 \% \mathrm{FJ}$ only but for completeness we also added an analysis including all the other studies available.

\section{Methods}

\section{Data sources and search strategy}

This meta-analysis was planned, conducted and reported according to the PRISMA statement [23]. The study protocol was preregistered (CRD42019135577). A systematic search of the available publications was performed using MEDLINE/PubMed, Web of Science, and Scopus, up to May 2019. The search was later updated to August 2019. The search strategy, without restrictions, included the expressions "fruit juice" AND "cardiovascular" OR "cerebrovascular" OR "stroke" OR "coronary heart" OR "blood pressure" OR "hypertension" OR "lipid" OR "cholesterol" OR "triglyceride" OR "HDL" OR "LDL" OR "glucose" OR "glycemia" OR "insulin" OR "HOMA" OR "weight" OR "BMI" OR "waist" OR "diabetes" OR "carotid" OR "flow mediated dilation" OR "pulse wave velocity" OR "arterial compliance" OR "arterial elasticity", or combinations thereof, either in medical subject headings or in the title/ abstract. Further information was retrieved through a manual search of references from recent reviews and relevant published original studies.

\section{Study selection and data extraction}

The data selection was conducted and reported in accordance with the PRISMA statement [23] by L.D., and was checked for accuracy by M.D. The titles and abstracts of the studies retrieved in the searches were screened to identify the studies that met the predefined inclusion criteria. The full texts of the potentially eligible studies were then retrieved and assessed for eligibility. Discrepancies over the inclusion of studies and the interpretation of data were resolved in conference with a third reviewer (P.S.). Data were then extracted from the studies selected for inclusion by L.D. in accordance with the PRISMA statement, and was checked for accuracy by M.D.

\section{Inclusion criteria}

To be included in the meta-analysis a published study had to meet the following criteria, stratified by study design:

Prospective studies (a) Original articles, (b) studies with a prospective design, (c) studies involving the adult population, (d) studies involving the assessment of $100 \%$ fruit juice $(100 \% \mathrm{FJ})[24]$ or of unspecified fruit drinks intake as the baseline exposure, (e) studies in which the patients have a diagnosis of cardiovascular (CV) disease (i.e., total cardiovascular events/mortality, coronary heart disease, stroke events/mortality) and/or are exposed to CV risk factors (e.g., hypertension, diabetes) which are determined prospectively as outcomes, (f) studies in which there is an indication of the number of participants exposed and the rate or number of events in the different categories of $100 \%$ FJ intake or of unspecified fruit drinks intake, $(\mathrm{g})$ studies in which there is an assessment of relative risk (RR) or hazard ratio (HR) for specified $100 \% \mathrm{FJ}$ or of unspecified fruit drink intake categories, (h) studies with a follow-up of at least 2 years (mean or median).

Intervention studies (a) Original articles, (b) randomized controlled trials (RCTs), (c) studies involving the adult population, (d) studies in which there is an indication of the difference in outcomes-among which CV risk factors (e.g., blood pressure, lipid profile, glucose homeostasis, body weight) or CV damage (e.g., arterial stiffness, intima media thickness, flow-mediated dilation)—between the intake of $100 \%$ FJ [24] and of control drink in one or more patient cohorts; (e) studies in which there are indications of the number of participants included in the exposed and control groups; (f) studies in which the length of intervention is at least 7 days. 


\section{Risk of bias}

The risk of bias of the studies included in the meta-analyses was assessed according to established criteria [25]: the Newcastle-Ottawa Scale was used for the evaluation of prospective studies [26], and the Cochrane risk of bias tool was applied for the evaluation of randomized controlled trials (RCTs) [27].

\section{Grading of evidence}

The quality of the entire body of evidence was evaluated using the GRADE (grading of recommendations assessment, development, and evaluation) methodology [28]. Evidence was graded as high, moderate or low quality. Observational studies started as low and RCTs as high by default. They were downgraded or upgraded based on specified criteria. Criteria to downgrade included study limitations (risk of bias), inconsistency (substantial unexplained heterogeneity), indirectness (factors that limit generalizability), imprecision (95\% CI cross a minimally important difference of 5\%, and publication bias (significant evidence of small-study effects). Criteria to upgrade certainty of evidence included a large magnitude of effect, a dose-response gradient, and attenuation by plausible confounding factors.

\section{Statistical analysis}

Meta-analysis on the prospective evaluation: the assessment of linear and non-linear association between $100 \%$ FJ or unspecified fruit drink consumption and outcomes was carried out. The possibility of non-linear relationship was explored by modelling $100 \%$ FJ or unspecified fruit drink consumption using restricted cubic splines with three knots at fixed percentiles (25, 50, and $75 \%$ ) of $100 \%$ FJ distribution. Departure from linearity was assessed by testing the null hypothesis that the coefficient of the second spline was equal to zero. A two-stage dose-response random-effects meta-analysis was performed $[29,30]$, which takes into account the correlation between the RR estimates across categories of $100 \%$ FJ or of unspecified fruit drink consumption. This analysis was carried out both to evaluate the effect in the single studies and to aggregate the results of all the studies. The median consumption for each specific category was assigned to each corresponding RR estimate. If the median consumption was not reported by the authors, the midpoint between the upper and lower boundary was used. If the lowest category was open-ended, its lower boundary was set to zero. If the upper boundary of the highest category was left unspecified, we assumed the category to be of the same amplitude as the preceding one. Statistical heterogeneity across the studies was also explored by $Q$-test.
Due to the small number of studies included in the prospective evaluation $(n<10)$, sensitivity, publication bias, sub-group and meta-regression analysis were not performed.

Further analyses were carried out including unspecified fruit drink study results. Separate dose-response analysis for unspecified fruit drink consumption was performed for stroke risk, coronary heart disease and diabetes risk.

For the meta-analysis of RCTs: mean differences (MDs) — and standard errors (SEs) — of the defined outcomes were extracted from the selected publications. The pooled weighted MD and 95\% CI were estimated using a randomeffect model. If these were not available, MD and SE were calculated from the comparison of the outcomes of $100 \%$ FJ and control drink intake [31]. The influence of a single cohort or of a particular study was estimated by sensitivity analysis. The Cochran $Q$ test and the $I^{2}$ statistic were used to evaluate statistical heterogeneity across the studies. Funnel plots were constructed and visually assessed for possible publication bias. Egger's weighted regression test and Begg's rank correlation test were also used to explore potential publication bias. In the case of significant funnel plot asymmetry, suggesting a number of possibly "missing" publications, the pooled estimate was recalculated based on the estimated number of "missing" studies and their effect sizes and SEs, a method known as "trim and fill".

Subgroup and meta-regression analyses were used to identify associations between risk of cardiovascular risk factors and relevant study characteristics as possible sources of heterogeneity: total participants, age, gender, BMI, country, year of publication, length of intervention, underlying disease status, baseline value of the outcome and variables potentially involved, serving size, type of $100 \%$ FJ, study design, comparator, level of feeding control, energy intake, energy difference between intervention and comparator, domains of risk of bias, and assessment methods for arterial stiffness. The additional analyses were not performed if there was a small number of cohorts for single outcome exploration $(n<10)$.

All statistical analyses were performed using the Stata Corp. software (version11.2; College Station, Texas, USA).

\section{Results}

Of a total of 16,762 publications retrieved, 21 prospective studies (8 reporting $100 \% \mathrm{FJ}$ and 13 unspecified fruit drinks) [11-17, 32-45] (Online Resource-Supplemental-Tables 4-5) and 35 RCTs [46-81] (Online Resource-Supplemental Table 6) were identified that met the inclusion criteria (Online Resource-Supplemental Fig. 1, Online ResourceSupplemental Table 7).

Prospective studies Of 21 prospective studies included in the meta-analysis: 10 studies reported data on $\mathrm{CV}$ risk 
[11-17, 32, 34] (Online Resource-Supplemental Table 4), nine studies reported the risk only for diabetes [36, 38-45], one study only for hypertension [37], and finally one study both for diabetes and hypertension, separately [35] (Online Resource-Supplemental Table 5).

Cardiovascular risk A total of ten studies were included in the meta-analysis of CV risk assessment [11-17, 32, 34]. One of the studies reported the results of three cohorts stratified by percentage of dietary energy from carbohydrates, hence we considered these cohorts separately [15]. Four studies reported analyses relative to the same cohorts (Nurses' Health Study-NHS and Health Professionals' Follow-Up Study-HPFS), but focusing on different outcomes. Thus, each study was used for the included in only one analysis of the respective outcome. Only three studies specified the results for $100 \% \mathrm{FJ}$ consumption $[13,14,17]$. All of them assessed $100 \% \mathrm{FJ}$ consumption by a validated structured selfadministered food frequency questionnaire according to the country meal pattern, containing specific questions on the average and type of fruit drinks consumption (EPIC [13, 14], Block [17]). In all the studies, the results were adjusted for the main confounders in multivariate models. All the studies had substantial high quality scores (Online ResourceSupplemental Table 5).

Diabetes risk. A total of ten studies were included in the meta-analysis of diabetes risk evaluation [35, 36, 38-45]. Only five studies specified the results for $100 \% \mathrm{FJ}$ consumption [35, 38, 42, 44, 45]. Three of them [38, 42, 45] assessed $100 \% \mathrm{FJ}$ consumption by a validated structured selfadministered food frequency questionnaire according to the country meal pattern, containing specific questions on the average and type of fruit drinks consumption (EPIC); while in the other two studies a validated structured food frequency questionnaire containing specific items on type and serving size of fruit drink intake was administered to all participants (Women's Health Initiative food frequency questionnaire [35], reduced version of Block [44]). In all but one study [44], the results were adjusted for the main confounders in multivariate models. All but one study had substantial high quality scores (Online Resource-Supplemental Table 5).

Hypertension risk. Only two studies were included in the analysis of hypertension development, but their risk expression was not comparable [35, 37] (Online Resource-Supplemental Table 5). These two studies assessed 100\%FJ intake by a validated food frequency questionnaire containing specific items on type and serving size of fruit drink intake administered to all participants (Women's Health Initiative food frequency questionnaire [35], Cardia dietary history [37]). One study included young participants with stringent criteria for diagnosis of hypertension [37]. The other one included post-menopausal women with common criteria for hypertension diagnosis [35].
Quality of body of evidence According to the GRADE criteria the evidence for the association between $100 \% \mathrm{FJ}$ consumption and $\mathrm{CV}$ risk was of moderate quality both for risk of $\mathrm{CV}$ events and diabetes risk. Despite the GRADE methodology defines observational evidence from cohort studies as low quality, there was an upgrade of the score due to dose-response gradient.

\section{Risk of total cardiovascular disease}

The analysis of the two studies that investigated the consumption of $100 \% \mathrm{FJ}$ and total CV events [13, 14] (overall, 65,018 participants and 4087 events, Online ResourceSupplemental Table 4) showed a non-linear association ( $p$ for non-linearity $=0.02$ ) (Fig. 1a). $100 \% \mathrm{FJ}$ consumption up to $170 \mathrm{ml}$ per day was associated with significantly lower risk of total $\mathrm{CV}$ events, with lowest risk at $78 \mathrm{ml}$ per day $(\mathrm{RR}=0.90,95 \%$ CI $0.83-0.97)$ compared with no $100 \% \mathrm{FJ}$ consumption (Fig. 1a). There was no significant heterogeneity $(p=0.97)$. On the other hand, a not significant effect of higher levels of reported $100 \% \mathrm{FJ}$ intake over $170 \mathrm{ml}$ per day was apparent compared with no $100 \%$ FJ consumption.

In addition, two studies that did not specify the type of fruit drink consumed analysed the risk of total CV events $[15,33]$ : in both cases, no significant association was detected between fruit drinks intake and risk of total $\mathrm{CV}$ events.

\section{Risk of stroke}

Two studies were available for the analysis of $100 \% \mathrm{FJ}$ intake and risk of stroke [13, 14] (overall, 65,018 participants and 1283 events, Online Resource-Supplemental Table 4). The analysis of departure from linearity for these two studies indicated a non-linear association between $100 \% \mathrm{FJ}$ consumption and stroke risk ( $p$ for non-linearity $=0.01$ ). A level of consumption up to $200 \mathrm{ml}$ per day was significantly associated with lower risk of stroke compared with no consumption, with lowest risk at $100 \% \mathrm{FJ}$ consumption of $78 \mathrm{ml}$ per day ( $R R=0.78,95 \%$ CI 0.66-0.92) (Fig. 1b). No heterogeneity was found $(p=0.44)$. By contrast, there was no significant effect of higher levels of reported $100 \% \mathrm{FJ}$ intake, above $200 \mathrm{ml}$ per day, compared with no $100 \% \mathrm{FJ}$ consumption.

Separate analysis of the studies with unspecified fruit drink intake $[11,12]$ (overall, three cohorts, 118,771 participants and 1039 events) again showed a non-linear association ( $p$ for non-linearity $=0.01$ ). Fruit drinks intake was significantly and inversely associated with risk of stroke at moderate consumption (Online Resource-Supplemental Fig. 2). The analysis did not detect significant heterogeneity $(p=0.88)$. 
Fig. 1 Dose-response association between $100 \%$ fruit juice consumption and cardiovascular events. a Risk of total cardiovascular (CV) events. b Risk of stroke events. $\mathbf{c}$ Risk of coronary heart disease (CHD). $100 \%$ fruit juice consumption was modelled with restricted cubic splines in a multivariate random-effects dose-response model (solid line). Dashed lines represent the $95 \%$ confidence intervals for the spline model

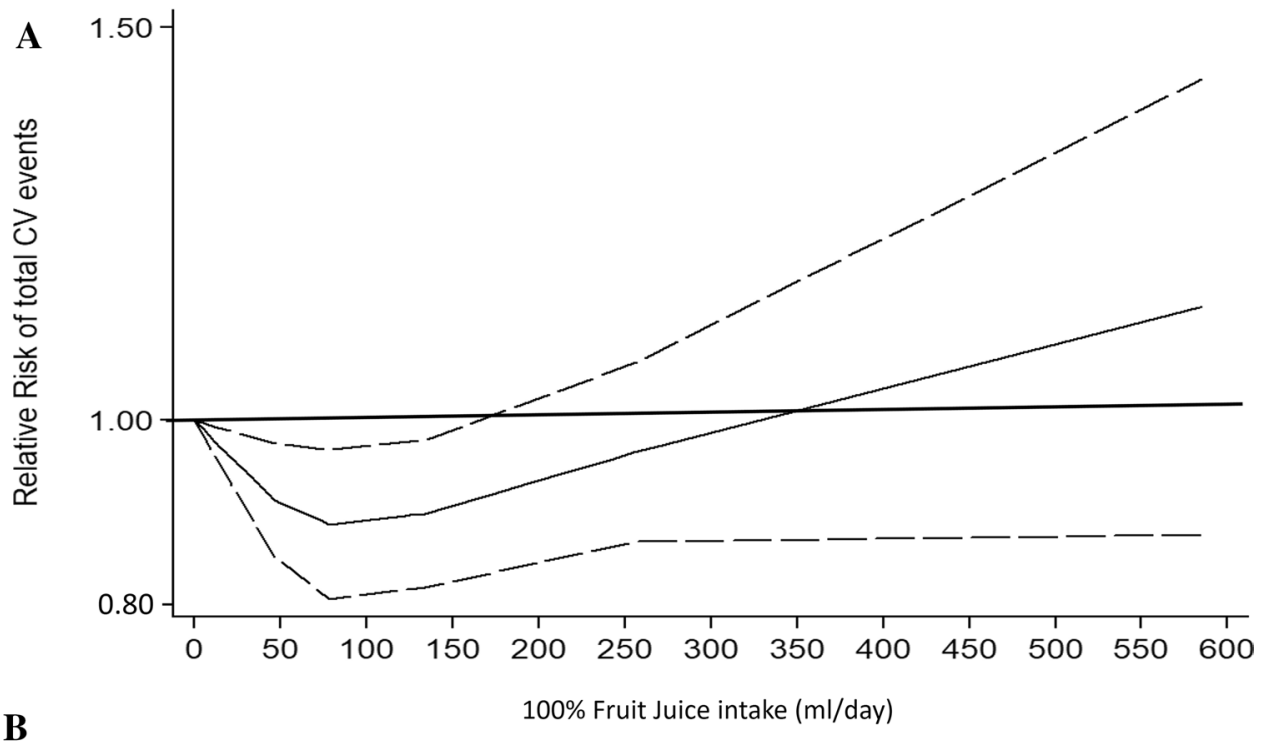

B

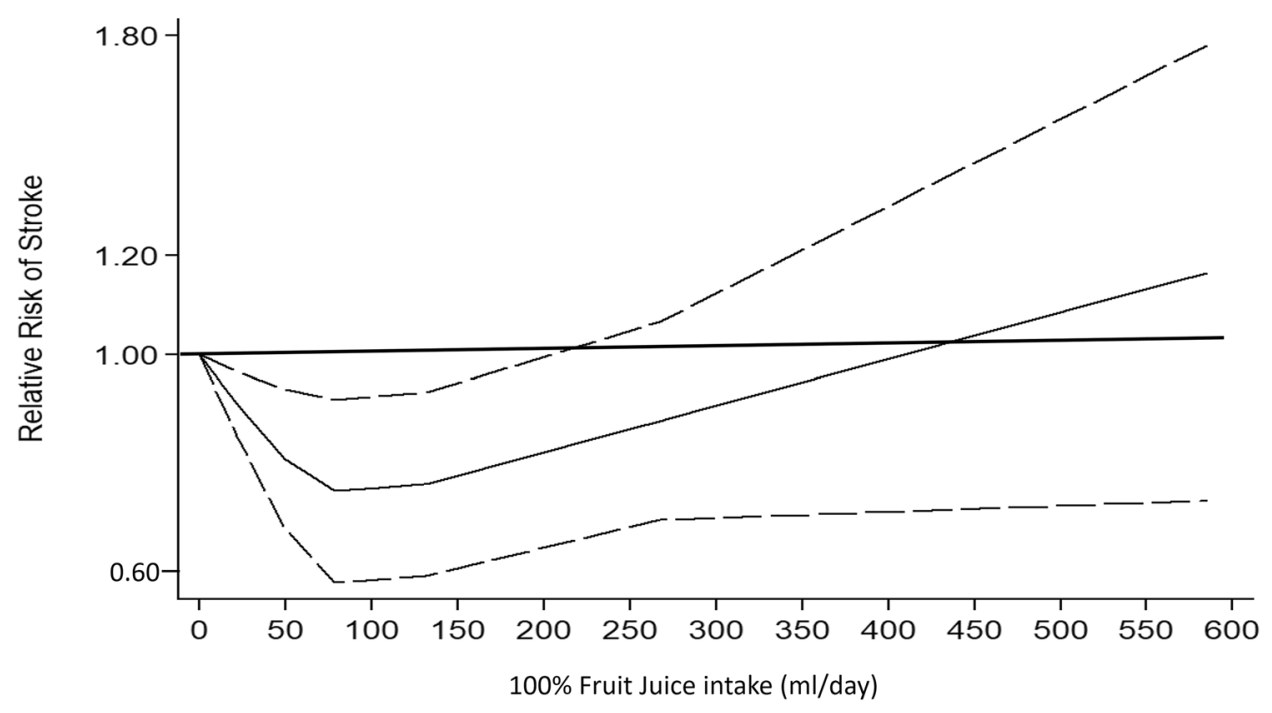

C

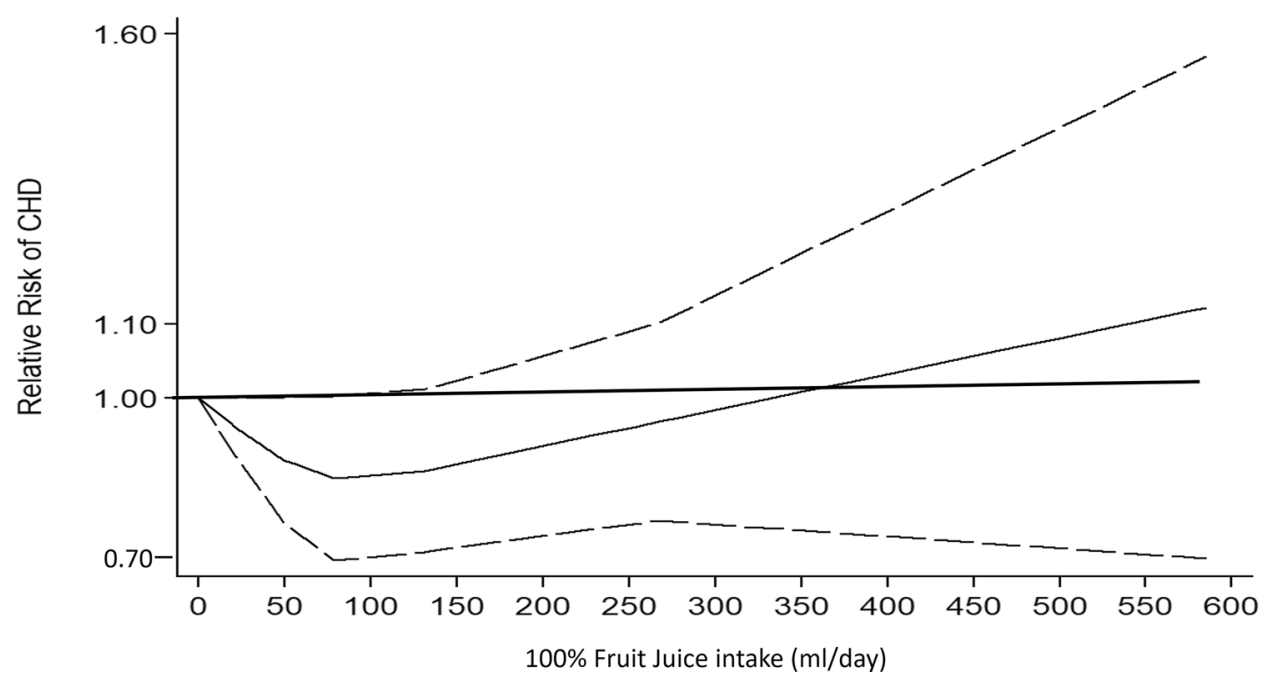




\section{Risk of coronary heart disease}

The analysis of the two studies that investigated the association between $100 \% \mathrm{FJ}$ intake and CHD [13, 14] (overall, 65,018 participants and 2273 events, Online ResourceSupplemental Table 4) indicated no significant association between any consumption of $100 \% \mathrm{FJ}$ and CHD risk ( $p$ for non-linearity $=0.15)($ Fig. 1c). There was no heterogeneity between studies $(p=0.41)$. A further study evaluated CHD risk for $100 \% \mathrm{FJ}$ intake, but there were no data available for dose-response analysis [17]. The main findings of this study indicated no significant increase in risk for a consumption of $350 \mathrm{ml} /$ day of $100 \% \mathrm{FJ}$ consumption.

Separate dose-response analysis of the studies with unspecified fruit drink intake [16, 34] (overall, 3 cohorts, 180,782 participants and 3265 events) showed no significant association between any consumption of fruit drinks and $\mathrm{CHD}$ risk ( $p$ for non-linearity $=0.86$ ) (Online Resource-Supplemental Fig. 3) and no evidence of heterogeneity among studies $(p=0.83)$. Other two studies not specifying the type of fruit drink consumed analysed the risk of CHD [12, 32], with data not available for dose-response analysis. In both studies, there was no association between fruit drink intake and CHD risk.

\section{Risk of diabetes}

The dose-response analysis of the five studies [35, 38, 42, 44, 45] (overall, 286,083 participants and 17,894 new diabetes cases, Online Resource-Supplemental Table 5) that reported $100 \% \mathrm{FJ}$ intake and risk of diabetes detected no significant association ( $p$ for non-linearity $=0.83$ ) (Fig. 2), without heterogeneity among studies $(p=0.41)$. Separate analysis with available data on the relationship between citrus $100 \% \mathrm{FJ}$ intake and diabetes risk [44, 45] showed similar results ( $p$ for non-linearity $=0.11$; heterogeneity, $\mathrm{p}=0.40)$ (Online Resource-Supplemental Fig. 3).

By contrast, additional analysis of the studies with unspecified fruit drink intake [36, 39-41, 43] (overall, five cohorts, 320,014 participants and 31,116 new diabetes cases, Online Resource-Supplemental Table 5) indicated a direct non-linear association between fruit drink consumption and risk of diabetes $(p$ for non-linearity $<0.001$ ) (Online Resource-Supplemental Fig. 5). There was significant heterogeneity among studies $(p=0.02)$.

$R C T$ s A total of 35 RCTs were included in the different meta-analyses (Online Resource-Supplemental-Table 6). Only one study provided multiple groups including different categories of patients [61]. Six studies assessed the arterial stiffness by pulse wave velocity (PWV) and four the endothelial function using flow-mediated dilation (FMD). The evaluation of the "risk of bias" indicated that the majority of the studies were substantially at moderate-risk (Online Resource-Supplemental Table 3). Quality of body of evidence: the GRADE methodology defines evidence from RCTs as high quality. This score was confirmed for the significant effect on BP and endothelial function and also for no effect on weight and lipids metabolism. For glucose metabolism, the quality was downgraded to moderate because of the large heterogeneity among studies.

The quality of the association between $100 \% \mathrm{FJ}$ intake and arterial stiffness was downgraded from high to moderate level because of heterogeneity among studies. However, the quality level achieved the high GRADE score when the evaluation was performed on only carotid-femoral PWV results.
Fig. 2 Dose-response association between $100 \%$ fruit juice consumption and risk of diabetes. $100 \%$ fruit juice consumption was modelled with restricted cubic splines in a multivariate random-effects dose-response model (solid line). Dashed lines represent the 95\% confidence intervals for the spline model

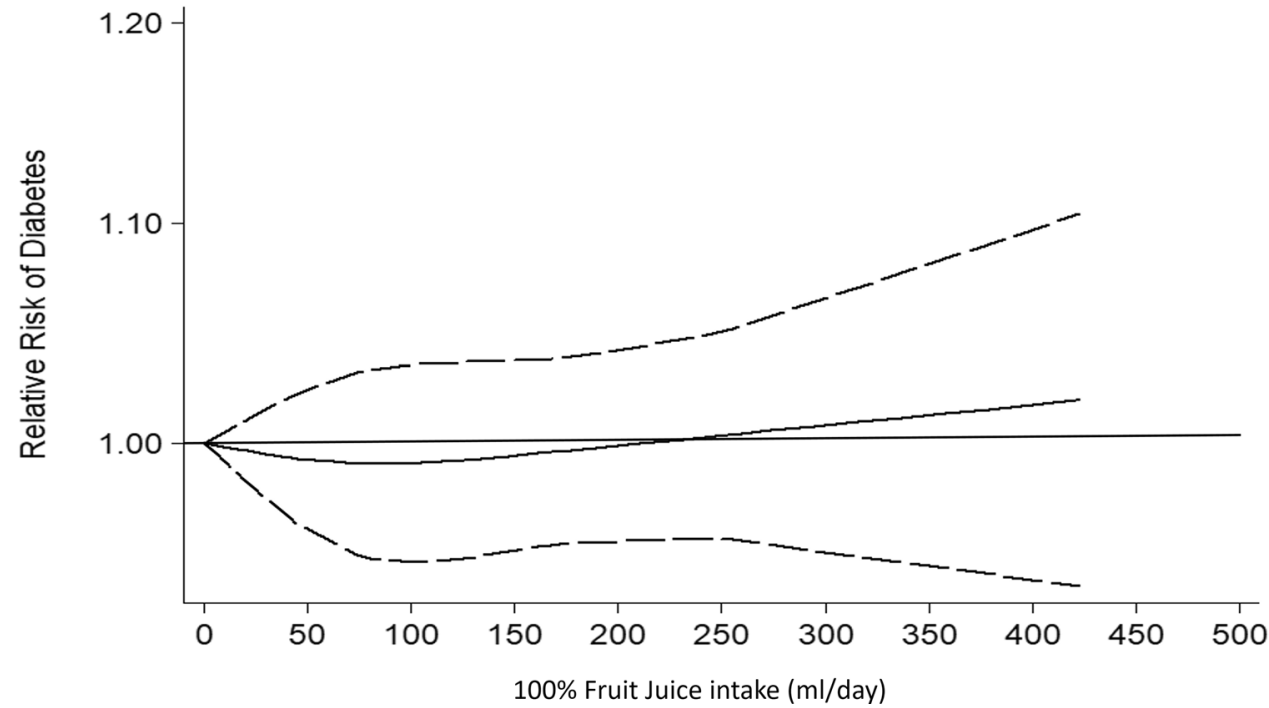




\section{Blood pressure}

The meta-analysis of the effects of $100 \% \mathrm{FJ}$ intake on brachial BP included 25 studies [47-49, 52-54, 56, 58, 61-73, 75, 76, 80, 81] (Online Resource-Supplemental Table 6). Pooled analyses showed a significant reduction of both systolic and diastolic BP upon $100 \% \mathrm{FJ}$ intake in comparison with placebo or control drink (Fig. 3, Table 1). There was low heterogeneity for diastolic BP (Table 1). Visual analysis of the funnel plot indicated little asymmetry (Online Resource-Supplemental Figs. 6-7), whereas Egger's and Begg's tests did not find significant evidence of publication bias. Also, the "trim and fill" method did not identify any possibly missing study. Sensitivity analysis showed that the average change in BP did not vary substantially when any individual study or cohort was excluded.

Additional analyses Only the study design was a significant source of heterogeneity for the effect on diastolic BP. Of note, sub-group analysis stratified by type of $100 \% \mathrm{FJ}$ consumed found that pomegranate juice significantly improved BP (Online Resource-Supplemental Table 8).

\section{Body weight}

Pooled analysis of the effect of $100 \% \mathrm{FJ}$ intake on body weight changes showed no significant association for all the specific outcomes considered: weight, BMI, and waist circumference $[46-48,50,52,53,57-65,71,72,75-80]$
Fig. 3 100\% fruit juice consumption and blood pressure. a Forest plot of the effect of $100 \%$ fruit juice intake on systolic blood pressure (BP). b Forest plot of the effect of $100 \%$ fruit juice intake on diastolic blood pressure (BP). Results are expressed as Mean Difference (MD) and 95\% confidence intervals (95\% CI). Squares indicate study-specific relative risk estimates (size of the square reflects the study-specific statistical weight); horizontal lines indicate $95 \% \mathrm{CI}$; diamond indicates the overall relative risk with its 95\% CI
A

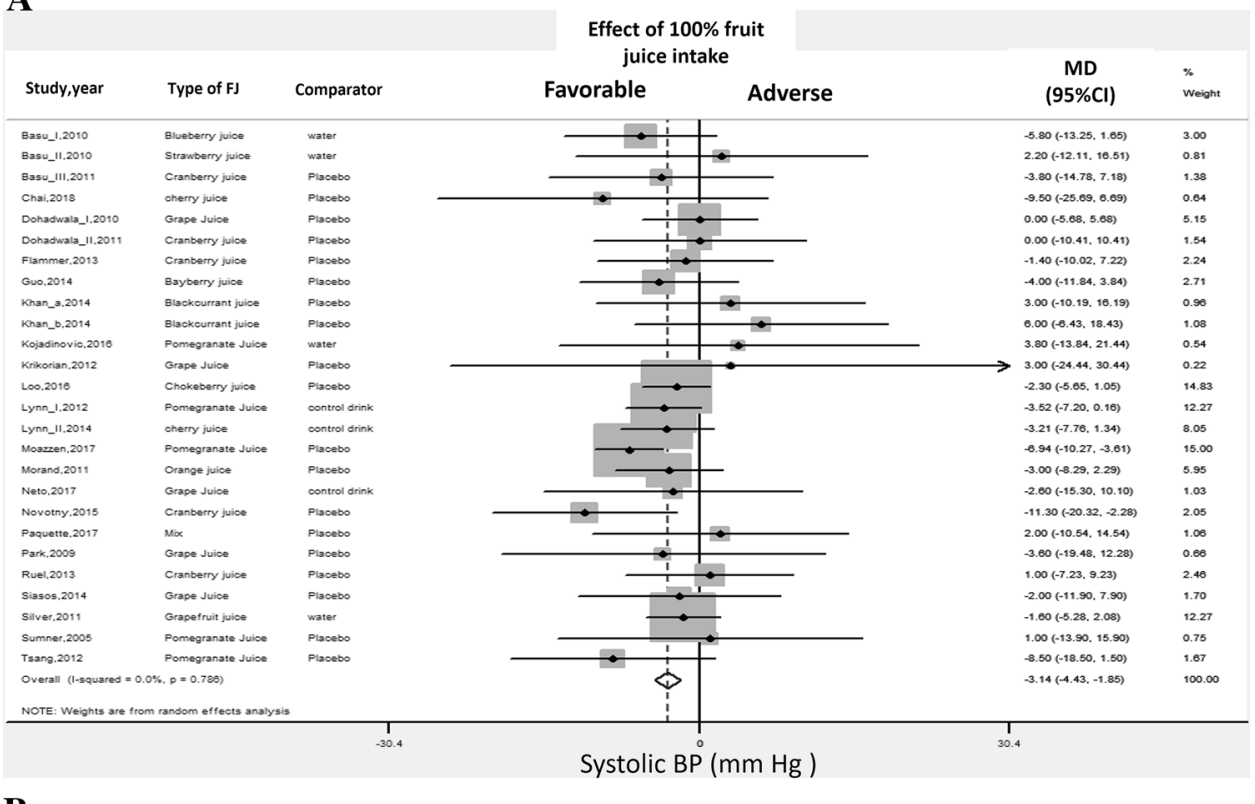

B

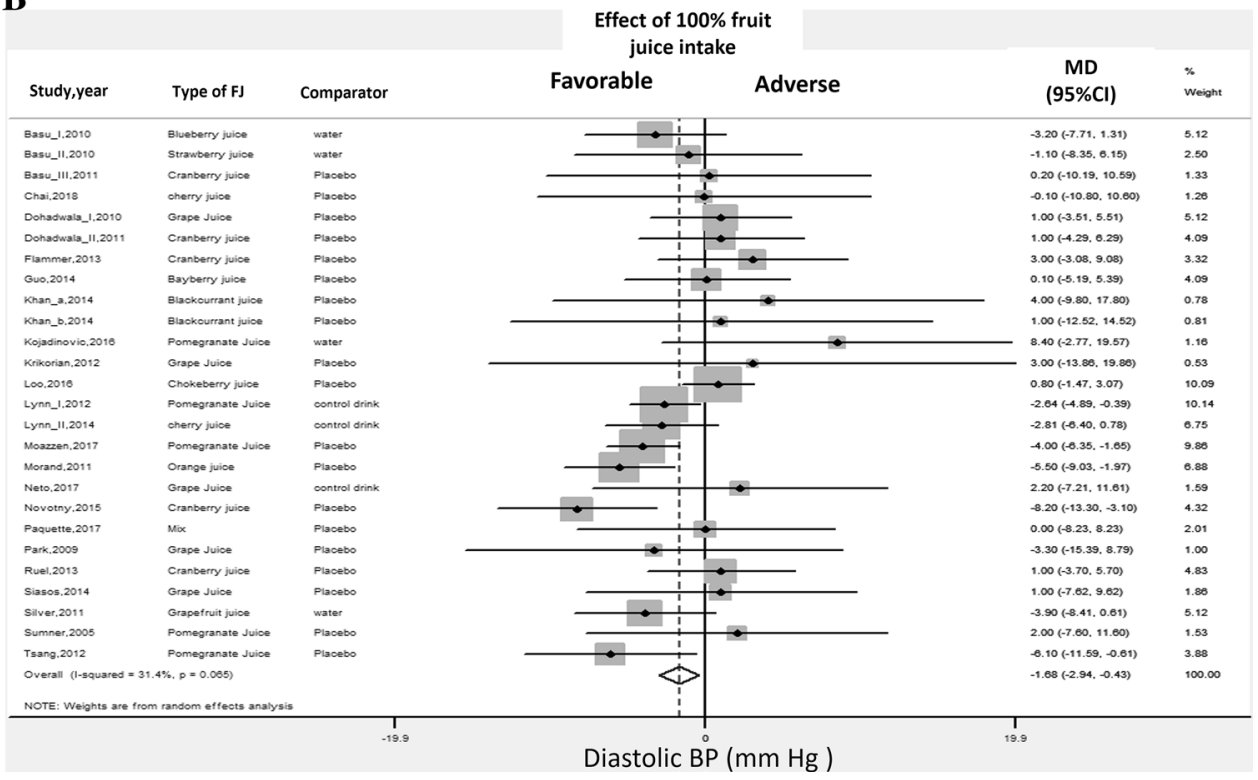


Table 1 Meta-analysis of the association between 100\% fruit juice intake and cardiovascular risk factors: results of randomised controlled trials

\begin{tabular}{|c|c|c|c|c|c|c|c|}
\hline Outcome & $\begin{array}{l}N \text { of Stud- } \\
\text { ies ( } N \text { of } \\
\text { cohorts) }\end{array}$ & $N$ of participants & $\begin{array}{l}\text { Average } \\
\text { intake }(\mathrm{ml} / \\
\text { day) }\end{array}$ & $\begin{array}{l}\text { Effect estimate } \\
\text { Mean difference } \\
(95 \% \mathrm{CI})\end{array}$ & $p$-value & Heterogeneity $p, I^{2}$ & $\begin{array}{l}\text { Publication bias- } \\
\text { Egger's test ( } p \text {-value; } \\
\text { Begg's test ( } p \text {-value) }\end{array}$ \\
\hline $\begin{array}{l}\text { Pulse wave } \\
\text { velocity }(\mathrm{m} / \mathrm{s}) \\
(53,54,65,66,75,81)\end{array}$ & $6(6)$ & 256 & 435 & $\begin{array}{l}-0.03(-0.41 \text { to } \\
0.35)\end{array}$ & 0.58 & $0.046,56 \%$ & $0.20 ; 0.30$ \\
\hline $\begin{array}{l}\text { Flow-mediated } \\
\text { dilation }(\%) \\
(50,54,61,75)\end{array}$ & $4(5)$ & 174 & 700 & $2.10 \%(1.14$ to 3.06$)$ & $<0.001$ & $0.5,0 \%$ & $0.12 ; 0.33$ \\
\hline \multicolumn{8}{|c|}{ Blood pressure $(47-49,52-54,56,58,61-73,75,76,80,81)$} \\
\hline $\begin{array}{l}\text { Systolic blood pres- } \\
\text { sure }(\mathrm{mm} \mathrm{Hg})\end{array}$ & $25(26)$ & 1032 & 447 & $\begin{array}{l}-3.14(-4.43 \text { to } \\
-1.85)\end{array}$ & $<0.001$ & $0.8,0 \%$ & $0.20 ; 0.40$ \\
\hline $\begin{array}{l}\text { Diastolic blood } \\
\text { pressure }(\mathrm{mm} \mathrm{Hg})\end{array}$ & $25(26)$ & 1032 & 447 & $\begin{array}{l}-1.68(-2.94 \text { to } \\
-0.43)\end{array}$ & $<0.001$ & $0.06,31 \%$ & $0.12 ; 0.22$ \\
\hline \multicolumn{8}{|c|}{ Body weight $(46-48,50,52,53,57-65,71,72,75-80)$} \\
\hline Weight $(\mathrm{kg})$ & $19(20)$ & 805 & 464 & $\begin{array}{l}-0.07(-0.39 \text { to } \\
0.25)\end{array}$ & 0.67 & $1.0,0 \%$ & $0.53 ; 0.40$ \\
\hline BMI $\left(\mathrm{kg} / \mathrm{m}^{2}\right)$ & $12(13)$ & 527 & 416 & $\begin{array}{l}-0.03(-0.15 \text { to } \\
0.10)\end{array}$ & 0.67 & $1.0,0 \%$ & $0.66 ; 0.39$ \\
\hline $\begin{array}{l}\text { Waist circumference } \\
(\mathrm{cm})\end{array}$ & $10(10)$ & 367 & 338 & $0.11(-0.94$ to 1.16$)$ & 0.84 & $1.0,0 \%$ & $0.95 ; 0.93$ \\
\hline \multicolumn{8}{|c|}{ Lipid metabolism (46-49,51-62,64,66-68,70-72,75-77,80,81) } \\
\hline $\begin{array}{l}\text { Total cholesterol } \\
(\mathrm{mg} / \mathrm{dl})\end{array}$ & $28(29)$ & 1,180 & 456 & $\begin{array}{l}-3.15(-6.43 \text { to } \\
0.13)\end{array}$ & 0.06 & $0.99,0 \%$ & $0.35 ; 0.38$ \\
\hline $\begin{array}{l}\text { LDL-cholesterol } \\
\qquad(\mathrm{mg} / \mathrm{dl})\end{array}$ & $23(23)$ & 880 & 429 & $0.29(-2.62$ to 3.20$)$ & 0.84 & $0.97,0 \%$ & $0.17 ; 0.10$ \\
\hline $\begin{array}{l}\text { HDL-cholesterol } \\
(\mathrm{mg} / \mathrm{dl})\end{array}$ & $25(25)$ & 1,007 & 414 & $0.43(-0.72$ to 1.59$)$ & 0.85 & $0.34,9 \%$ & $0.10 ; 0.30$ \\
\hline $\begin{array}{l}\text { Triglycerides (mg/ } \\
\text { dl) }\end{array}$ & $26(26)$ & 1,049 & 422 & $\begin{array}{l}-0.65(-5.83 \text { to } \\
4.52)\end{array}$ & 0.80 & $1.0,0 \%$ & $0.77 ; 0.47$ \\
\hline \multicolumn{8}{|c|}{ Glucose metabolism $(47-54,57-59,62-64,67,68,70,74-81)$} \\
\hline Glucose (mg/dl) & $23(23)$ & 845 & 409 & $\begin{array}{l}-1.01(-4.02 \text { to } \\
2.00)\end{array}$ & 0.51 & $<0.01,69 \%$ & $0.92 ; 0.85$ \\
\hline HOMA index (U) & $11(11)$ & 487 & 415 & $0.01(-0.28$ to 0.30$)$ & 0.50 & $0.66,0 \%$ & $0.80 ; 0.70$ \\
\hline Insulin $(\%)$ & $11(11)$ & 424 & 430 & $3.4(-7.2$ to 14.0$)$ & 0.53 & $0.88,0 \%$ & $0.80 ; 0.70$ \\
\hline $\begin{array}{l}\text { Glycated haemoglo- } \\
\text { bin }(\%)\end{array}$ & $3(3)$ & 120 & 323 & $\begin{array}{l}-0.10(-0.31 \text { to } \\
0.10)\end{array}$ & 0.32 & $0.98,0 \%$ & - \\
\hline
\end{tabular}

(Table 1, Online Resource-Supplemental Table 6, Fig. 4). For all the outcomes, there was no significant heterogeneity among studies and no evidence of publication bias (Table 1, Online Resource-Supplemental Figs. 8-10). Sensitivity analysis showed that the average change in different body weight expressions did not vary substantially with the exclusion of any individual study or cohort.

Additional analyses No study characteristics affected the relationship between $100 \% \mathrm{FJ}$ intake and body weight changes by meta-regression and subgroup analysis (Online Resource-Supplemental Table 9).

\section{Lipid profile}

The analyses of the effect of $100 \% \mathrm{FJ}$ intake on the lipid metabolic profile did not detect any significant association for total cholesterol, LDL-cholesterol, HDL-cholesterol, and triglycerides [46-49, 51-62, 64, 66-68, 70-72, 75-77, 80, 81] (Table 1, Online Resource-Supplemental Table 6, Online Resource-Supplemental Figs. 11-14). There was no significant heterogeneity among studies (Table 1), and no evidence of publication bias (Online Resource-Supplemental Figs. 15-18). The evaluation of single study effect did not 
Fig. 4 100\% fruit juice consumption and body weight. a Forest plot of the effect of $100 \%$ fruit juice intake on weight. b Forest plot of the effect of $100 \%$ fruit juice intake on BMI. c Forest plot of the effect of $100 \%$ fruit juice intake on waist circumference. Results are expressed as Mean Difference (MD) and 95\% confidence intervals (95\% CI). Squares indicate study-specific relative risk estimates (size of the square reflects the study-specific statistical weight); horizontal lines indicate $95 \% \mathrm{CI}$; diamond indicates the overall relative risk with its 95\% CI
A
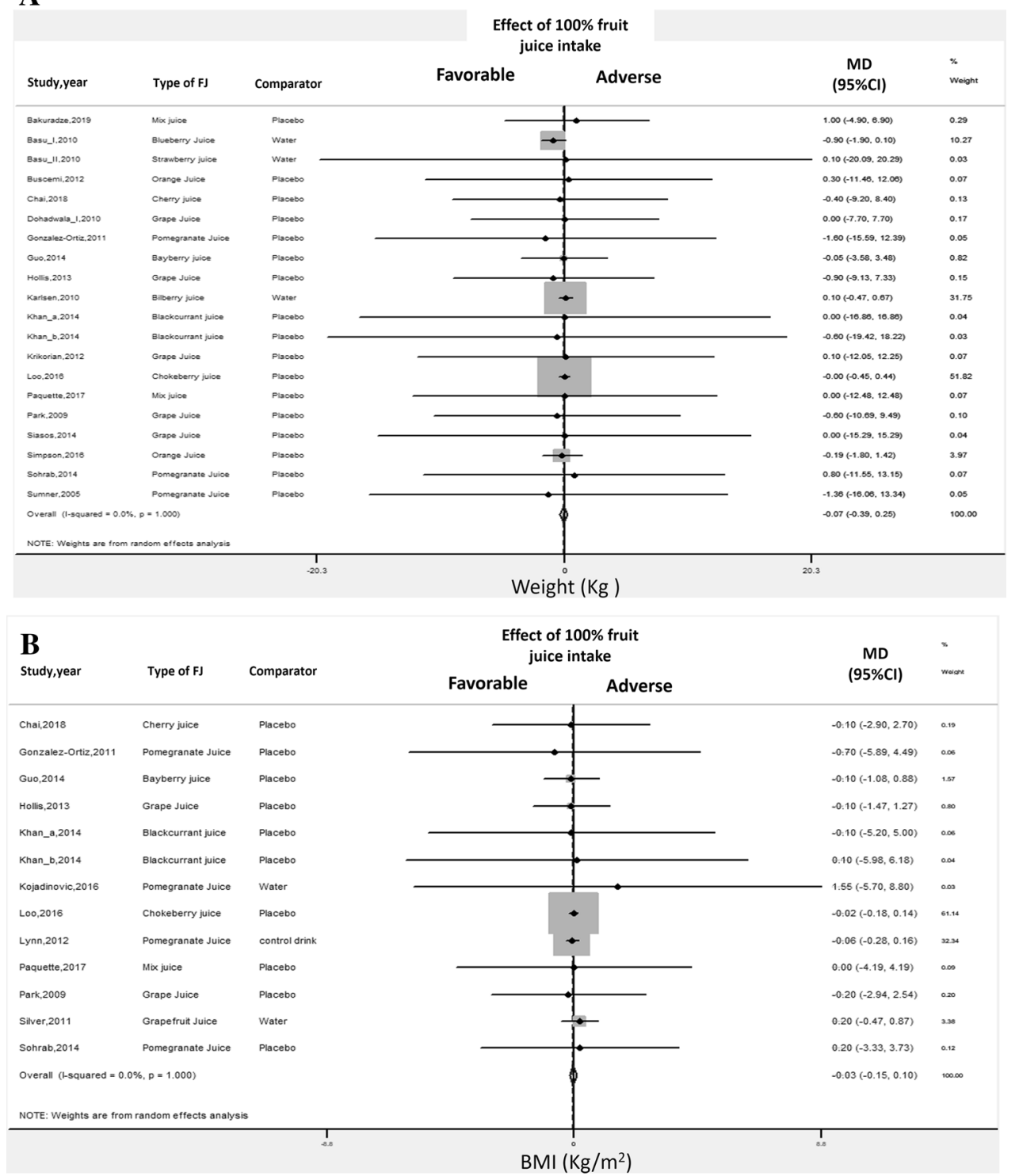

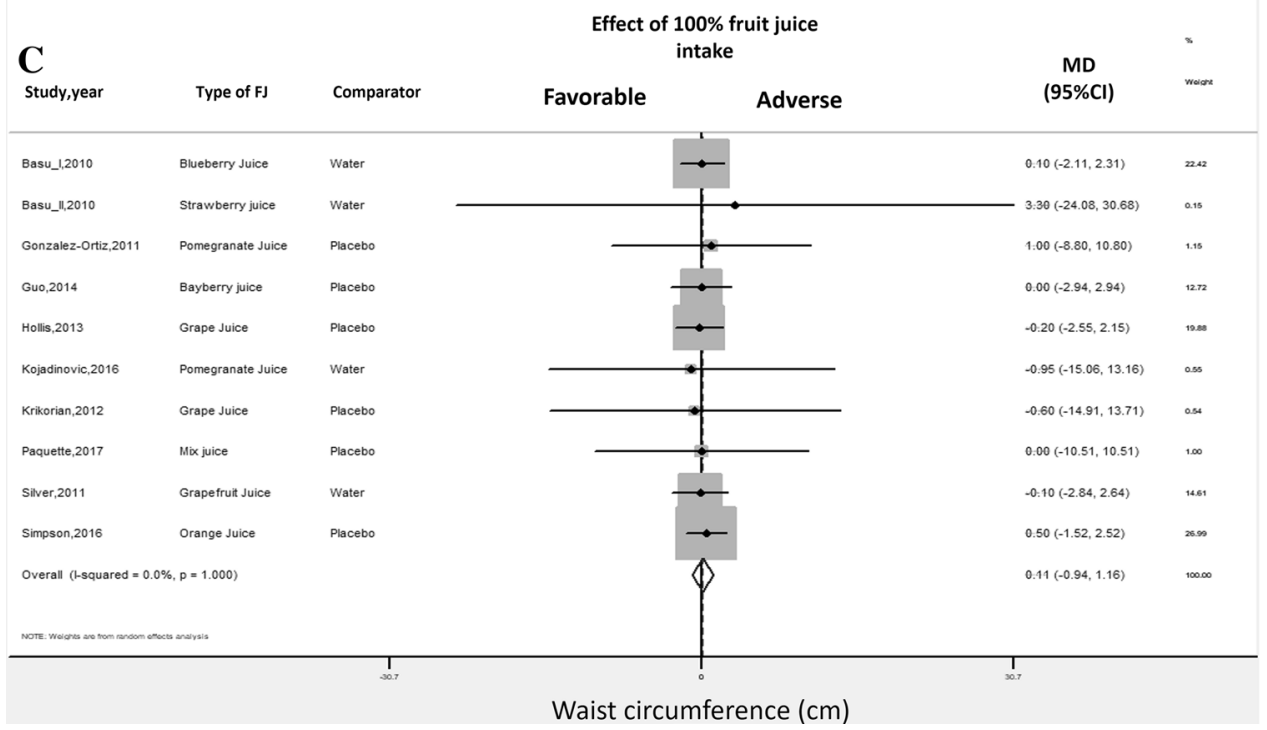


show significant associations for any of the included studies. However, only for total cholesterol, sensitivity analysis indicated a significant inverse association between cholesterol changes and $100 \% \mathrm{FJ}$ intake after exclusion of a few single studies.

Additional analyses Age and features of the participants, design of the studies, type of comparator used, characteristics of $100 \% \mathrm{FJ}$, and diet during the studies were significant sources of heterogeneity on changes of HDL-cholesterol (Online Resource-Supplemental Table 10).

\section{Glucose metabolism}

Pooled analysis of the effect of $100 \% \mathrm{FJ}$ intake on glucose metabolism showed no significant association for all the outcomes considered: serum glucose, HOMA index, serum insulin, and glycated haemoglobin $[47-54,57-59,62-64$, 67, 68, 70, 74-81] (Table 1, Online Resource-Supplemental Table 6, Online Resource-Supplemental Figs. 19-22). Significant heterogeneity was observed only for serum glucose (Table 1). Visual analysis of the funnel plot indicated little asymmetry only for changes in glucose levels (Online Resource-Supplemental Figs. 23-25), but the formal tests did not find significant evidence of publication bias (Table 1). Sensitivity analysis showed that the average change in the different outcome levels did not vary substantially with the exclusion of any individual study.

Additional analyses Meta-regression and subgroup analyses found gender, country of origin, characteristics of $100 \% \mathrm{FJ}$ and study design as significant sources of heterogeneity about the effect of $100 \% \mathrm{FJ}$ intake on serum glucose (Online Resource-Supplemental Table 11). Analysis of the features that may affect changes in HOMA index detected only the type and the energy content of the comparator as significant sources of heterogeneity (Online Resource-Supplemental Table 11).

\section{Arterial stiffness}

In the pooled analysis of six RCTs [53, 54, 65, 66, 75, 81] (Online Resource-Supplemental Table 6), 100\%FJ intake was not associated with changes in PWV (Table 1, Online Resource-Supplemental Fig. 26). There was significant heterogeneity among studies (Table 1). Visual analysis of the funnel plot indicated little asymmetry (Online ResourceSupplemental Fig. 27), whereas formal tests did not find significant evidence of publication bias (Table 1). Of note, changes in BP did not affect changes in PWV.

Separate analysis including only the studies using the carotid-femoral PWV changes (i.e., the gold standard for measuring large artery stiffness) [53, 54, 75, 81] (four studies, 162 total participants) indicated a significant beneficial effect of $100 \% \mathrm{FJ}$ intake compared with the comparator drink
(MD: $-0.38 \mathrm{~m} / \mathrm{s} ; p=0.04)$. In addition, the analysis did not detect heterogeneity among studies (Online ResourceSupplemental Fig. 26).

\section{Flow-mediated dilation}

Pooled analysis of four RCTs [50, 54, 61, 75] (Online Resource-Supplemental Table 6) showed that $100 \% \mathrm{FJ}$ intake was significantly associated with increased FMD compared with the comparator drink (Table 1, Online Resource-Supplemental Fig. 28). There was no significant heterogeneity among studies and no evidence of publication bias (Table 1, Online Resource-Supplemental Fig. 29). Sensitivity analysis showed that the average change in FMD did not vary substantially when any individual cohort was excluded. Even in this case, changes in BP did not affect changes in FMD.

\section{Discussion}

\section{Main study results}

Our meta-analysis indicated that $100 \% \mathrm{FJ}$ consumption is not associated with increased CV risk. Prospective data support a non-linear dose-response association between $100 \%$ FJ consumption and the rate of incident stroke and total CV disease, with evidence of a statistically significant beneficial effect at low-moderate intake $(\sim 80 \mathrm{ml} /$ day $)$. There was no significant association between $100 \%$ FJ consumption and risk of CHD or diabetes. The results of the RCTs support a beneficial effect on $\mathrm{CV}$ risk due to the favourable impact of $100 \% \mathrm{FJ}$ intake on BP levels, arterial compliance and endothelial function. A neutral effect was detected on body weight, lipid profile and glucose metabolism. The results were supported by the GRADE categorization that detected high quality of the results for RCTs and moderate quality for prospective studies.

The results on $\mathrm{CV}$ risk were strengthened by no evidence of heterogeneity among studies. While, in general, our results are consistent with the trend found by a previous systematic review [82], relevant elements of novel information of the present meta-analysis include separate assessment of the studies with specified $100 \%$ FJ intake, detailed dose-response analysis with detection in some cases of nonlinear relationships, and assessment of the quality of the results by GRADE categorization.

Our results are also substantially in agreement with a recent study of a European population [14, 83] showing a non-linear relationship between $100 \% \mathrm{FJ}$ consumption and CV risk with significant benefit at low-moderate consumption.

By contrast, they are at variance with another recent study on a large American population, in which a very high $100 \%$ 
FJ intake was associated with significantly higher CHD death rate [17]. The latter study had major limitations in the small number of CHD-related deaths, in the very large amount of $100 \% \mathrm{FJ}$ intake considered for the assessment of risk, in the probable misclassification of $100 \% \mathrm{FJ}$ intake and in the lack of assessment of a potential dose-response relationship.

\section{$100 \% \mathrm{FJ}$ intake, BP and arterial function}

The beneficial effect of moderate $100 \% \mathrm{FJ}$ intake on $\mathrm{CV}$ risk, in particular on the risk of stroke, is supported by the results on BP. Pooled analysis of a large number of studies showed that $100 \% \mathrm{FJ}$ intake was associated with a reduction of more than $3 \mathrm{mmHg}$ for systolic and approximately $2 \mathrm{mmHg}$ for diastolic BP. Compared with previous meta-analyses of the effects of $100 \% \mathrm{FJ}$ intake on BP, our study used more stringent inclusion criteria and adopted a robust methodology for the assessment of potential sources of heterogeneity, potential publication bias, robustness and quality of results. Furthermore, we explored for the first time the effect of $100 \%$ FJ intake on arterial stiffness, an expression of $\mathrm{CV}$ organ damage [1]. In this regard, the analysis of the RCTs that used carotid-femoral PWV as a proxy for arterial stiffness did show a significant and favourable effect of $100 \%$ FJ. In line with this result are the findings on endothelial function: pooled analysis of FMD, another expression of early $\mathrm{CV}$ damage [84], found a significant improvement upon 100\% FJ intake, with no significant heterogeneity among studies, no effect dependent on BP changes, and a high quality level as suggested by GRADE score.

Unfortunately, only two studies explored the risk to develop hypertension as a function of the consumption of fruit drinks [35, 37] (Online Resource-Supplemental Table 5). One American study, including young participants, suggested a significant and inverse trend between fruit drinks intake and risk of hypertension [37]. The other American study, including a large post-menopausal female sample, found a not significant association between $100 \% \mathrm{FJ}$ consumption and development of hypertension at different levels of intake [35].

\section{Possible mechanisms involved}

Although our study has not the potential to shed light on pathophysiological mechanisms, it is conceivable that the relatively high amount of minerals, vitamins and bioactive compounds associated with $100 \% \mathrm{FJ}$ consumption explain the benefit on CV risk [5, 85] and, in particular, on arterial stiffness, endothelial function, BP and risk of stroke.

In addition to the clinical and epidemiological evidence [85-87], many studies in animal models indicated that a high potassium intake may reduce $\mathrm{CV}$ organ damage, even independently from its effect on BP $[88,89]$. A meta-analysis of RCTs suggested a beneficial effect of potassium intake on arterial stiffness [90].

Among the bioactive substances highly bioavailable in $100 \%$ FJ, polyphenols (e.g., hesperidin, naringenin) may contribute to the cardiovascular benefit, in particular by modulation of the nitric oxide (NO)-cGMP pathway. These compounds may regulate the levels and the activity of endothelial NO synthase and therefore NO bioavailability [68, 91, 92], also involving intracellular $\mathrm{Ca}^{2+}[93]$. Polyphenols also cause inhibition of platelet aggregation, enhance release of platelet-derived NO, and reduce superoxide production [91, 94], oxidative DNA damage [55] and lipid peroxidation [95-97]. In addition, experimental studies suggested that hesperidin, the major polyphenol contained in orange juice, exerts its anti-inflammatory and antioxidant effects also by suppression of gene expression of some proinflammatory cytokines (e.g., TNF-a, IL-1 $\beta$, IL-6) $[98,99]$, reduction of the expression of the intercellular adhesion molecule-1 (ICAM-1) [100], and production of metalloproteinases [94].

Also the antioxidant activity of vitamins may support the beneficial CV effect of 100\% FJ intake. Vitamin A and derivatives were reported to reduce coronary heart disease risk [101] and this was attributed to modulation of endothelial cells differentiation and increase in NO synthesis [102-104]. A high content of Vitamin C may contribute to endothelium-dependent vasodilation by increasing $\mathrm{NO}$ availability [105], in particular by modulation of endothelial NO synthase [106]. Vitamin E decreases cell adhesion molecule expression [107] and monocyte adhesion to the endothelium [108]. Finally, folic acid content may exert beneficial effects on CV risk, by reducing homocysteine production and its detrimental effects [109, 110].

Based on the available evidence and on the results of our analyses, a biphasic dose-response relationships apparent, where the beneficial effect detected at lowmoderate $100 \%$ FJ consumption may be explained by the favourable health effect of "low dose" bioactive substances [111]. On the contrary, at a high level of consumption, the benefit may be offset by the unfavourable consequences of excess sugar and calorie intake [111].

Although there is an almost complete lack of studies comparing the effects on health outcomes of low-moderate consumption of $100 \% \mathrm{FJ}$ with those of equivalent amounts of fresh fruit [76], it is indeed conceivable that the latter would be at least as beneficial as $100 \% \mathrm{FJ}$ because of the higher content of fibre and in many cases of the other beneficial compounds. Actually, the benefit associated with $100 \% \mathrm{FJ}$ intake in observational studies may result from partial compensation of a generally inadequate fresh fruit consumption at the population level. 


\section{$100 \% \mathrm{FJ}$ intake, adiposity and risk of diabetes}

$100 \% \mathrm{FJ}$ intake in our study appeared to have a neutral effect on adiposity in all its expressions. Noteworthy, none of the included RCTs show significant changes in body weight upon $100 \% \mathrm{FJ}$ consumption. These results are in line with the recent prospective study by Garduño-Alanís et al. in 5000 Russian individuals indicating no significant BMI increase after 3 years of follow-up in $100 \% \mathrm{FJ}$ consumers [112]. Likewise, in a study on a large sample of post-menopausal women, $100 \%$ FJ consumption was associated with only a small not clinically relevant increase in weigh after 3 years of follow-up [113]. A similar not clinically relevant increase in BMI was also found in children and adolescents by a recent meta-analysis of prospective studies [114].

Other experimental investigations, in particular those on citrus $100 \% \mathrm{FJ}$, did not indicate a detrimental effect on body weight and actually suggested that citrus extracts may induce lipolysis [115, 116] and reduce fat accumulation [117], also by modulation of gut microbiota [118].

Our systematic review did not detect a significant association between $100 \%$ FJ consumption and risk of diabetes and in this respect our results are in general consistent with those of previous meta-analyses [119, 120]. One of these indeed showed that the consumption of unspecified fruit drinks was associated with an increased risk of diabetes whereas that of $100 \% \mathrm{FJ}$ was not [119]. In another recent meta-analysis by Imamura et al. [120] the consumption of sugary drinks and $100 \% \mathrm{FJ}$ in excess of $250 \mathrm{ml}$ per day was also associated with a significant increase in the risk of diabetes. Our dose-response analysis detected a non-linear significant direct association between fruit drinks consumption and risk of diabetes but no association for $100 \% \mathrm{FJ}$ or citrus $100 \% \mathrm{FJ}$ intake. At variance with previously reported experimental data [3, 4], our pooled analysis of RCTs indicated no significant association between $100 \%$ FJ intake and several parameters of glucose metabolism. In particular, 100\% FJ intake did not affect serum levels of glucose and insulin nor the HOMA index. In addition, from the analysis of three available studies, there was no significant association with glycated-haemoglobin levels, further supporting a long-term neutral effect. These results confirm those found in previous meta-analyses $[21,22]$.

\section{$100 \%$ FJ intake and lipid profile}

The exploration of the lipid profile showed no significant effect of $100 \%$ FJ intake in our meta-analysis. Previous systematic reviews as well as some experimental study reported a beneficial effect on lipid profile with consumption of $100 \%$ FJ [121-123].

\section{Strengths and limitations}

This study has several strengths: (a) the evaluation of both prospective and intervention studies; (b) the stringent inclusion criteria; (c) a large number of participants for prospective evaluation and a large number of studies for intervention assessment; (d) the robustness of the findings by sensitivity and sub-group analysis; (e) the comprehensive exploration of possible sources of heterogeneity; (f) the substantially low heterogeneity among studies and no evidence of publication bias; $(\mathrm{g})$ the evaluation of shape and strength of the dose-response relationship; (h) the assessment of overall quality of evidence using the GRADE assessment approach.

On the other hand, the study also has limitations. For prospective studies, their observational nature impairs conclusions about possible cause-effect relationships.

Also the questionnaire to assess the extent of $100 \% \mathrm{FJ}$ consumption is subject to limitations in prospective studies both in the administered and the self-administered version, because of potential misclassification of quantity and quality of $100 \% \mathrm{FJ}$ consumption.

The heterogeneity in the characteristics of the included studies is an important limitation, in particular for the RCTs, which varied for age, health status, type of $100 \%$ FJ utilized, serving size and comparator, length of intervention. This limitation was explored by sub-group and meta-regression analysis, which in general found little evidence of subgroup differences. However, in some subgroup analyses, the test was performed including relatively few studies in one of the subgroups, hence in those cases definitive conclusions cannot be reached. In the analysis of prospective studies, an important source of heterogeneity may be the different serving size due to geographical location, but this limitation was dealt with by dose-response analysis. Furthermore, although all the included prospective studies adjusted for several relevant confounding factors (including age, body mass index, and other $\mathrm{CV}$ risk factors), residual confounding by other potential factors cannot be ruled out.

This meta-analysis was not able to detect consistent effects of individual types of $100 \% \mathrm{FJ}$, apart for the effect of pomegranate juice on BP, because of the low number of studies in each subgroup. Of note, a focused evaluation of the citrus/orange $100 \%$ FJ effect, the most popular juice worldwide, suggests substantial similar results of this type of juice as compared to the unspecified $100 \% \mathrm{FJ}$ both for CV outcomes [13, 14] and diabetes risk [35, 44, 45]. There was also heterogeneity with regard to the fruit juices or fruit juice preparations used in the RCTs: nevertheless, the effects observed in the studies that reported on reconstituted $100 \% \mathrm{FJ}$ or fruit juices as such were not significantly different. 
Also, because few studies evaluated the effect of $100 \% \mathrm{FJ}$ on $\mathrm{CV}$ organ damage, only the effect on arterial stiffness was explored by this meta-analysis. About CV organ damage, our systematic search detected only two studies that examined the effect of $100 \%$ FJ on other outcomes (i.e., carotid intima-media thickness) $[124,125]$. One RCT, including approximately 300 participants at moderate CHD risk and with a relatively high intima-media thickness, found a not significant reduction in these values after 1 year of $240 \mathrm{ml}$ of pomegranate juice supplementation [125]. The other one, non RCT, found progressively lower values in ten participants, during 1 year of $50 \mathrm{ml}$ of pomegranate juice supplementation [124].

Finally, further limitations are given by the relatively small number of prospective studies and cohorts available, by the residual possibility of publication bias and by the difficulty to draw definitive conclusions with regard to the interaction with age, gender and race given the peculiar composition of the study cohorts available. This notwithstanding, the observational design and the process of metaanalysis, with the calculation of a pooled estimate of the effect and the dose-response analysis in a large number of participants, are functional to overcome at least in part this problem.

\section{Conclusions}

The results of our study show that low-moderate $100 \%$ FJ consumption is not associated with increased risk of CV disease and that actually it is associated with apparent benefit against the development of $\mathrm{CV}$ events through a non-linear relationship. The positive changes in $\mathrm{BP}$, arterial compliance and endothelial function may help explain the effect of $100 \%$ FJ intake on risk of $\mathrm{CV}$ disease, in particular on stroke risk. These findings are in keeping with the inverse association also occurring between regular fresh fruit consumption and risk of $\mathrm{CV}$ disease.

Given the importance of CV diseases [9, 10, 126, 127] and the popularity of fruit drinks consumption around the world [7, 8], the relationship between $100 \% \mathrm{FJ}$ and $\mathrm{CV}$ risk assumes considerable relevance. Therefore, to clearly classify $100 \%$ FJ from unspecified fruit drink is crucial both for future research and for correct consumption. Further properly powered RCTs of the effect of long-term moderate $100 \% \mathrm{FJ}$ consumption are warranted to determine possible cause-effect relationships, to disentangle the effects of different types of $100 \%$ FJ (e.g., orange juice), and to overcome the currently limited evidence with respect to the interactions with age, ethnicity and diseases. In particular, intervention studies with carefully controlled intake of $100 \%$ FJ should evaluate the mechanisms of its effects on BP and $\mathrm{CV}$ organ damage to extend current knowledge in this field.

\section{Implications for public health}

Based on recent data, the overall average consumption of $100 \% \mathrm{FJ}$ is $38 \mathrm{ml}$ per day [7], with women's consumption being higher than that of men. Recent European estimates found an average consumption of $49 \mathrm{ml}$ per day, with highest consumption in Western $(52 \mathrm{ml})$ and lowest in Eastern countries $(29 \mathrm{ml})$ [8].

International dietary guidelines are not in agreement on recommendations about $100 \% \mathrm{FJ}$ consumption. In the United States, the Guidelines for Healthy Eating recommend the daily consumption of two cups-equivalent of fruit (one cup $=237 \mathrm{ml}$ ), of which less than half can be taken as 100\% FJ [128]. For the American Heart Association, one of the recommended portions of fruit can be replaced by the consumption of $100 \% \mathrm{FJ}(1 / 2 \mathrm{cup}=115 \mathrm{ml})$ [129]. In the United Kingdom, the dietary guidelines suggest that $100 \%$ FJ can contribute one portion of the daily fruit portion size $(150 \mathrm{ml})$ [130]. Conversely, Dutch and Italian guidelines suggest more caution on $100 \%$ FJ consumption. Both guidelines do not recommend the consumption of $100 \% \mathrm{FJ}$ in place of fresh fruit, because one classified $100 \% \mathrm{FJ}$ in the category of sugar-containing beverages [131], and the Italian guidelines consider it as "unnecessary" consumption [132].

While fresh fruit in the proper amounts cannot be surrogated by processed fruit consumption, the results of our study indicate no harm for the adult population from lowmoderate $100 \% \mathrm{FJ}$ consumption and suggest that low-moderate consumption of $100 \% \mathrm{FJ}$ in the context of a balanced diet and as an alternative to sugar-sweetened beverages needs not to be discouraged. Although these results also show that high levels of $100 \%$ FJ intake were not associated with a detrimental $\mathrm{CV}$ effect, it would be hazardous to try to reach any conclusion on "safe levels" of intake, given the few prospective data available and the high heterogeneity of the level of consumption between trials and prospective studies. Therefore, only general consideration can be made. Indeed, it seems reasonable to suggest particular caution by overweight and obese individuals and by anyone else at higher risk of diabetes mellitus. Furthermore, more research is warranted to compare the effects on health outcomes of low-moderate consumption of $100 \% \mathrm{FJ}$ with that of equivalent amounts of fresh fruit, given the almost complete lack of sound information available in this respect $[75,133]$.

Acknowledgements We thank Dr. Roberto Volpe (SIPREC) for the comments to preliminary version of the document. *100\% Fruit JuiceSINU Working Group. Alessandra Bordoni (Dipartimento Scienze e Tecnologie Agro-Alimentari, Alma Mater Studiorum Università di Bologna), Pasquale Strazzullo (Dipartimento Medicina Clinica e Chirurgia, Università di Napoli "Federico II"), Giulia Cairella (UOSD Promozione della Salute, Piani di Prevenzione e Medicina dello Sport ASL Roma 2), Maria Cristina Casiraghi (Dipartimento Scienze per gli Alimenti, la Nutrizione e l'Ambiente, DeFENS, Università degli Studi di Milano), Lanfranco D'Elia (Dipartimento Medicina Clinica e 
Chirurgia, Università di Napoli "Federico II"), Valeria del Balzo (Università di Roma La Sapienza), Monica Dinu (Dipartimento di Medicina Sperimentale e Clinica, Università degli Studi di Firenze ), Daniela Erba (Dipartimento Scienze per gli Alimenti, la Nutrizione e l'Ambiente, DeFENS, Università degli Studi di Milano), Francesca Garbagnati, Andrea Ghiselli (Centro di Ricerca per gli Alimenti e la Nutrizione, CREA, Roma), Nicoletta Pellegrini (Dipartimento di Scienze Agroalimentari, Ambientali e Animali, Università degli Studi di Udine ), Alessandro Pinto (Università di Roma La Sapienza), Laura Rossi (Centro di Ricerca per gli Alimenti e la Nutrizione, CREA, Roma), Gian Luigi Russo (Istituto di Scienze dell'Alimentazione, CNR, Avellino), Francesca Scazzina (Dipartimento degli Alimenti e del Farmaco, Università degli Studi di Parma), Umberto Scognamiglio (Centro di Ricerca per gli Alimenti e la Nutrizione, CREA, Roma), Francesco Sofi (Dipartimento di Medicina Sperimentale e Clinica, Università degli Studi di Firenze), Salvatore Vaccaro (F.A. Nutrizione Clinica e Centro Metabolico ad Interesse Oncologico, P.O. "Arcispedale Santa Maria Nuova"; Azienda Unità Sanitaria Locale - I.R.C.C.S. di Reggio Emilia), Elvira Verduci (Dipartimento di Scienze della Salute, Università degli studi di Milano).

Author contributions Contributed to conception and design: LD, PS; contributed to acquisition data: $\mathrm{LD}, \mathrm{MD}$; contributed to analysis: $\mathrm{LD}$, PS; contributed to interpretation: LD, MD, SF, PS; first draft of the article: LD, MD; critically revised manuscript: FS, MV, PS, and SINU working group; gave final approval of the article: all authors and SINU working Group.

Funding Open access funding provided by Università degli Studi di Napoli Federico II within the CRUI-CARE Agreement. This project was funded by the European Fruit Juice Association (AIJN) via an unrestricted grant. AIJN was not involved in the design, conduction, analysis and interpretation of the results.

\section{Compliance with ethical standards}

Conflict of interest The Authors declare that there is no conflict of interest.

Ethical approval Part of the preliminary study data was previously presented at the Italian Society of Human Nutrition (SINU) 2019 Meeting.

Open Access This article is licensed under a Creative Commons Attribution 4.0 International License, which permits use, sharing, adaptation, distribution and reproduction in any medium or format, as long as you give appropriate credit to the original author(s) and the source, provide a link to the Creative Commons licence, and indicate if changes were made. The images or other third party material in this article are included in the article's Creative Commons licence, unless indicated otherwise in a credit line to the material. If material is not included in the article's Creative Commons licence and your intended use is not permitted by statutory regulation or exceeds the permitted use, you will need to obtain permission directly from the copyright holder. To view a copy of this licence, visit http://creativecommons.org/licenses/by/4.0/.

\section{References}

1. Williams B, Mancia G, Spiering W, Agabiti Rosei E, Azizi M, Burnier M, Clement DL, Coca A, de Simone G, Dominiczak A, Kahan T, Mahfoud F, Redon J, Ruilope L, Zanchetti A, Kerins M, Kjeldsen SE, Kreutz R, Laurent S, Lip GYH, McManus R, Narkiewicz K, Ruschitzka F, Schmieder RE, Shlyakhto E,
Tsioufis C, Aboyans V, Desormais I (2018) 2018 ESC/ESH Guidelines for the management of arterial hypertension: the Task Force for the management of arterial hypertension of the European Society of Cardiology and the European Society of Hypertension: the Task Force for the management of arterial hypertension of the European Society of Cardiology and the European Society of Hypertension. J Hypertens 36(10):1953-2041. https ://doi.org/10.1097/HJH.0000000000001940

2. Whelton PK, Carey RM, Aronow WS, Casey DE Jr, Collins KJ, Dennison Himmelfarb C, DePalma SM, Gidding S, Jamerson KA, Jones DW, MacLaughlin EJ, Muntner P, Ovbiagele B, Smith SC Jr, Spencer CC, Stafford RS, Taler SJ, Thomas RJ, Williams KA Sr, Williamson JD, Wright JT Jr (2018) 2017 ACC/AHA/ AAPA/ABC/ACPM/AGS/APhA/ASH/ASPC/NMA/PCNA guideline for the prevention, detection, evaluation, and management of high blood pressure in adults: a report of the American college of cardiology/American heart association task force on clinical practice guidelines. J Am Coll Cardiol 71:e127-248

3. Hanhineva K, Törrönen R, Bondia-Pons I, Pekkinen J, Kolehmainen M, Mykkänen H, Poutanen K (2010) Impact of dietary polyphenols on carbohydrate metabolism. Int J Mol Sci 11(4):1365-1402

4. Kerimi A, Gauer JS, Crabbe S, Cheah JW, Lau J, Walsh R, Cancalon PF, Williamson G (2019) Effect of the flavonoid hesperidin on glucose and fructose transport, sucrase activity and glycaemic response to orange juice in a crossover trial on healthy volunteers. Br J Nutr 121(7):782-792. https://doi.org/10.1017/S0007 114519000084

5. Siasos G, Tsigkou V, Tousoulis D, Kokkou E, Oikonomou E, Vavuranakis M, Basdra EK, Papavassiliou AG, Stefanadis C (2013) Flavonoids in atherosclerosis: an overview of their mechanisms of action. Curr Med Chem 20:2641-2660

6. Zheng J, Zhou Y, Li S, Zhang P, Zhou T, Xu DP, Li HB (2017) Effects and mechanisms of fruit and vegetable juices on cardiovascular diseases. Int J Mol Sci 18:555

7. Singh GM, Micha R, Khatibzadeh S, Shi P, Lim S, Andrews KG, Engell RE, Ezzati M, Mozaffarian D, Global burden of diseases nutrition and chronic diseases expert group (NutriCoDE), (2015) Global, regional, and national consumption of sugar-sweetened beverages, fruit juices and milk: a systematic assessment of beverage intake in 187 Countries. PLoS ONE 10:e124845

8. https://aijn.eu/files/attachments/.598/2018_Liquid_Fruit_Marke t_Report.pdf. Accessed 2 Jan 2020

9. GBD 2013 Mortality and Causes of Death Collaborators (2015) Global, regional, and national age-sex specific all-cause and cause-specific mortality for 240 causes of death, 1990-2013: a systematic analysis for the Global Burden of Disease Study 2013. Lancet 385:117-171

10. World Health Organization (2002) The world health report 2002_reducing risks promoting healthy life. WHO, Geneva, Switzerland. https://www.who.int/whr/2002/en/whr02_en.pdf. Accessed 1 Aug 2019

11. Joshipura KJ, Ascherio A, Manson JE, Stampfer MJ, Rimm EB, Speizer FE, Hennekens CH, Spiegelman D, Willett WC (1999) Fruit and vegetable intake in relation to risk of ischemic stroke. JAMA 282:1233-1239. https://doi.org/10.1001/ jama.282.13.1233

12. Mink PJ, Scrafford CG, Barraj LM, Harnack L, Hong CP, Nettleton JA, Jacobs DR Jr (2007) Flavonoid intake and cardiovascular disease mortality: a prospective study in postmenopausal women. Am J Clin Nutr 85:895-909. https://doi.org/10.1093/ ajcn/85.3.895

13. Lai HT, Threapleton DE, Day AJ, Williamson G, Cade JE, Burley VJ (2015) Fruit intake and cardiovascular disease mortality in the UK Women's Cohort Study. Eur J Epidemiol 30:1035-1048. https://doi.org/10.1007/s10654-015-0050-5 
14. Scheffers FR, Boer JMA, Verschuren WMM, Verheus M, van der Schouw YT, Sluijs I, Smit HA, Wijga AH (2019) Pure fruit juice and fruit consumption and the risk of CVD: the European Prospective Investigation into Cancer and Nutrition-Netherlands (EPIC-NL) study. Br J Nutr 121(3):351-359. https://doi. org/10.1017/S0007114518003380

15. Joshipura KJ, Hung HC, Li TY, Hu FB, Rimm EB, Stampfer MJ, Colditz G, Willett WC (2009) Intakes of fruits, vegetables and carbohydrate and the risk of CVD. Public Health Nutr 12:115121. https://doi.org/10.1017/S1368980008002036

16. Hansen L, Dragsted LO, Olsen A, Christensen J, Tjønneland A, Schmidt EB, Overvad K (2010) Fruit and vegetable intake and risk of acute coronary syndrome. Br J Nutr 104(2):248-255. https://doi.org/10.1017/S0007114510000462

17. Collin LJ, Judd S, Safford M, Vaccarino V, Welsh JA (2019) Association of sugary beverage consumption with mortality risk in US adults: a secondary analysis of data from the REGARDS Study. JAMA Netw Open 3 2(5):e193121. https:// doi.org/10.1001/jamanetworkopen.2019.3121

18. Liu K, Xing A, Chen K, Wang B, Zhou R, Chen S, Xu H, Mi M (2013) Effect of fruit juice on cholesterol and blood pressure in adults: a meta-analysis of 19 randomized controlled trials. PLoS ONE 8:e61420

19. Sahebkar A, Ferri C, Giorgini P, Bo S, Nachtigal P, Grassi D (2017) Effects of pomegranate juice on blood pressure: a systematic review and meta-analysis of randomized controlled trials. Pharmacol Res 115:149-161. https://doi.org/10.1016/j. phrs.2016.11.018

20. Pourmasoumi M, Hadi A, Najafgholizadeh A, Joukar F, Mansour-Ghanaei F (2019) The effects of cranberry on cardiovascular metabolic risk factors: a systematic review and metaanalysis. Clin Nutr. https://doi.org/10.1016/j.clnu.2019.04.003

21. Wang B, Liu K, Mi M, Wang J (2014) Effect of fruit juice on glucose control and insulin sensitivity in adults: a meta-analysis of 12 randomized controlled trials. PLoS ONE 9(4):e95323

22. Murphy MM, Barrett EC, Bresnahan KA, Barraj LM (2017) $100 \%$ Fruit juice and measures of glucose control and insulin sensitivity: a systematic review and meta-analysis of randomised controlled trials. J Nutr Sci 6(e59):1-15

23. Moher D, Liberati A, Tetzlaff J, Altman DG (2009) Preferred reporting items for systematic reviews and meta-analyses: the PRISMA statement. BMJ 339(b2535):20

24. Directive 2012/12/EU of the European Parliament and of the Council, amending Council Directive 2001/112/EC relating to fruit juices and certain similar products intended for human consumption (2012) Official Journal of the European Union. https://eur-lex.europa.eu/LexUriServ/LexUriServ.do?uri=OJ: L:2012:115:0001:0011:EN:PDF. Accessed 1 Aug 2019

25. Higgins JPT, Thomas J, Chandler J, Cumpston M, Li T, Page MJ, Welch VA (eds) (2019) Cochrane handbook for systematic reviews of interventions, 2nd edn. John Wiley \& Sons, Chichester

26. Wells GA, Shea B, O'Connell D, Peterson J, Welch V, Losos M, Tugwell P. The Newcastle-Ottawa Scale (NOS) for assessing the quality of nonrandomised studies in meta-analyses. https://www. ohri.ca/programs/clinical_epidemiology/oxford.asp. Accessed 1 August 2019

27. Higgins JPT, Savović J, Page MJ, Elbers RG, Sterne JAC. Chapter 8: Assessing risk of bias in a randomized trial. Cochrane Handbook for Systematic Reviews of Interventions. https:// training.cochrane.org/handbook/current/chapter-08. Accessed 1 August 2019

28. Schünemann H, Brożek J, Guyatt G, and Oxman A (2013) GRADE Handbook. Handbook for grading the quality of evidence and the strength of recommendations using the GRADE approach. Updated October 2013. https://gdt.gradepro.org/app/ handbook/handbook.html. Accessed 1 August 2019

29. Greenland S, Longnecker MP (1992) Methods for trend estimation from summarized dose-response data, with applications to meta-analysis. Am J Epidemiol 135:1301-1309

30. Orsini N, Li R, Wolk A, Khudyakov P, Spiegelman D (2012) Meta-analysis for linear and nonlinear dose-response relations: examples, an evaluation of approximations, and software. Am J Epidemiol 175:66-73

31. Weir CJ, Butcher I, Assi V, Lewis SC, Murray GD, Langhorne P, Brady MC (2018) Dealing with missing standard deviation and mean values in meta-analysis of continuous outcomes: a systematic review. BMC Med Res Methodol 18(1):25. https:// doi.org/10.1186/s12874-018-0483-0

32. Simila ME, Kontto JP, Mannisto S, Valsta LM, Virtamo J (2013) Glycaemic index, carbohydrate substitution for fat and risk of CHD in men. Br J Nutr 110:1704-1711. https://doi.org/10.1017/ S0007114513000858

33. Hung HC, Joshipura KJ, Jiang R, Hu FB, Hunter D, SmithWarner SA, Colditz GA, Rosner B, Spiegelman D, Willett WC (2004) Fruit and vegetable intake and risk of major chronic disease. J Natl Cancer Inst 96:1577-1584. https://doi.org/10.1093/ jnci/djh296

34. Joshipura KJ, Hu FB, Manson JE, Stampfer MJ, Rimm EB, Speizer FE, Colditz G, Ascherio A, Rosner B, Spiegelman D, Willett WC (2001) The effect of fruit and vegetable intake on risk for coronary heart disease. Ann Intern Med 134:1106-1114. https ://doi.org/10.7326/0003-4819-134-12-200106190-00010

35. Auerbach BJ, Littman AJ, Tinker L, Larson J, Krieger J, Young B, Neuhouser M (2017) Associations of 100\% fruit juice versus whole fruit with hypertension and diabetes risk in postmenopausal women: results from the Women's Health Initiative. Prev Med 105:212-218. https://doi.org/10.1016/j.ypmed.2017.08.031

36. Bazzano LA, Li TY, Joshipura KJ, Hu FB (2008) Intake of fruit, vegetables, and fruit juices and risk of diabetes in women. Diabetes Care 31(7):1311-1317. https://doi.org/10.2337/dc08-0080

37. Duffey KJ, Gordon-Larsen P, Steffen LM, Jacobs DR Jr, Popkin BM (2010) Drinking caloric beverages increases the risk of adverse cardiometabolic outcomes in the Coronary Artery Risk Development in Young Adults (CARDIA) Study. Am J Clin Nutr 92(4):954-959. https://doi.org/10.3945/ajcn.2010.29478

38. Fagherazzi G, Vilier A, Saes Sartorelli D, Lajous M, Balkau B, Clavel-Chapelon F (2013) Consumption of artificially and sugarsweetened beverages and incident type 2 diabetes in the Etude Epidemiologique aupres des femmes de la Mutuelle Generale de l'Education Nationale-European Prospective Investigation into Cancer and Nutrition cohort. Am J Clin Nutr 97(3):517-523. https://doi.org/10.3945/ajcn.112.050997

39. InterAct Consortium (2013) Consumption of sweet beverages and type 2 diabetes incidence in European adults: results from EPIC-InterAct. Diabetologia 56(7):1520-1530. https://doi. org/10.1007/s00125-013-2899-8

40. Muraki I, Imamura F, Manson JE, Hu FB, Willett WC, van Dam RM, Sun Q (2013) Fruit consumption and risk of type 2 diabetes: results from three prospective longitudinal cohort studies. BMJ 347:f5001. https://doi.org/10.1136/bmj.f5001

41. Mursu J, Virtanen JK, Tuomainen TP, Nurmi T, Voutilainen S (2014) Intake of fruit, berries, and vegetables and risk of type 2 diabetes in Finnish men: the Kuopio Ischaemic Heart Disease Risk Factor Study. Am J Clin Nutr 99(2):328-333. https://doi. org/10.3945/ajen.113.069641

42. O'Connor L, Imamura F, Lentjes MA, Khaw KT, Wareham NJ, Forouhi NG (2015) Prospective associations and population impact of sweet beverage intake and type 2 diabetes, and effects of substitutions with alternative beverages. Diabetologia 58(7):1474-1483. https://doi.org/10.1007/s00125-015-3572-1 
43. Odegaard AO, Koh WP, Yuan JM, Pereira MA (2015) Beverage habits and mortality in Chinese adults. J Nutr 145:595-604. https ://doi.org/10.3945/jn.114.200253

44. Palmer JR, Boggs DA, Krishnan S, Hu FB, Singer M, Rosenberg L (2008) Sugar-sweetened beverages and incidence of type 2 diabetes mellitus in African American women. Arch Intern Med 168(14):1487-1492. https://doi.org/10.1001/archi nte.168.14.1487

45. Scheffers FR, Wijga AH, Verschuren WMM, van der Schouw YT, Sluijs I, Smit HA, Boer JMA (2020) Pure fruit juice and fruit consumption are not associated with incidence of type 2 diabetes after adjustment for overall dietary quality in the European Prospective Investigation into Cancer and Nutrition-Netherlands (EPIC-NL) Study. J Nutr. https://doi.org/10.1093/jn/nxz340

46. Bakuradze T, Tausend A, Galan J, Maria Groh IA, Berry D, Tur JA, Marko D, Richling E (2019) Antioxidative activity and health benefits of anthocyanin-rich fruit juice in healthy volunteers. Free Radic Res 4:1-11. https://doi.org/10.1080/10715 762.2019.1618851

47. Basu A, Du M, Leyva MJ, Sanchez K, Betts NM, Wu M, Aston CE, Lyons TJ (2010) Blueberries decrease cardiovascular risk factors in obese men and women with metabolic syndrome. J Nutr 140(9):1582-1587. https://doi.org/10.3945/jn.110.124701

48. Basu A, Fu DX, Wilkinson M, Simmons B, Wu M, Betts NM, Du M, Lyons TJ (2010) Strawberries decrease atherosclerotic markers in subjects with metabolic syndrome. Nutr Res 30(7):462469. https://doi.org/10.1016/j.nutres.2010.06.016

49. Basu A, Betts NM, Ortiz J, Simmons B, Wu M, Lyons TJ (2011) Low-energy cranberry juice decreases lipid oxidation and increases plasma antioxidant capacity in women with metabolic syndrome. Nutr Res 31(3):190-196. https://doi.org/10.1016/j. nutres.2011.02.003

50. Buscemi S, Rosafio G, Arcoleo G, Mattina A, Canino B, Montana M, Verga S, Rini G (2012) Effects of red orange juice intake on endothelial function and inflammatory markers in adult subjects with increased cardiovascular risk. Am J Clin Nutr 95(5):1089-1095. https://doi.org/10.3945/ajcn.111.031088

51. Cerdá B, Soto C, Albaladejo MD, Martínez P, Sánchez-Gascón F, Tomás-Barberán F, Espín JC (2006) Pomegranate juice supplementation in chronic obstructive pulmonary disease: a 5-week randomized, double-blind, placebo-controlled trial. Eur J Clin Nutr 60(2):245-253. https://doi.org/10.1038/sj.ejcn.1602309

52. Chai SC, Davis K, Wright RS, Kuczmarski MF, Zhang Z (2018) Impact of tart cherry juice on systolic blood pressure and lowdensity lipoprotein cholesterol in older adults: a randomized controlled trial. Food Funct 9(6):3185-3194. https://doi.org/10.1039/ c8fo00468d

53. Dohadwala MM, Hamburg NM, Holbrook M, Kim BH, Duess MA, Levit A, Titas M, Chung WB, Vincent FB, Caiano TL, Frame AA, Keaney JF Jr, Vita JA (2010) Effects of Concord grape juice on ambulatory blood pressure in prehypertension and stage 1 hypertension. Am J Clin Nutr 92(5):1052-1059. https:// doi.org/10.3945/ajen.2010.29905

54. Dohadwala MM, Holbrook M, Hamburg NM, Shenouda SM, Chung WB, Titas M, Kluge MA, Wang N, Palmisano J, Milbury PE, Blumberg JB, Vita JA (2011) Effects of cranberry juice consumption on vascular function in patients with coronary artery disease. Am J Clin Nutr 93(5):934-940. https://doi.org/10.3945/ ajcn. 110.004242

55. Duthie SJ, Jenkinson AM, Crozier A, Mullen W, Pirie L, Kyle J, Yap LS, Christen P, Duthie GG (2006) The effects of cranberry juice consumption on antioxidant status and biomarkers relating to heart disease and cancer in healthy human volunteers. Eur $\mathbf{J}$ Nutr 45(2):113-122. https://doi.org/10.1007/s00394-005-0572-9

56. Flammer AJ, Martin EA, Gössl M, Widmer RJ, Lennon RJ, Sexton JA, Loeffler D, Khosla S, Lerman LO, Lerman A (2013)
Polyphenol-rich cranberry juice has a neutral effect on endothelial function but decreases the fraction of osteocalcin-expressing endothelial progenitor cells. Eur J Nutr 52(1):289-296. https:// doi.org/10.1007/s00394-012-0334-4

57. González-Ortiz M, Martínez-Abundis E, Espinel-Bermúdez MC, Pérez-Rubio KG (2011) Effect of pomegranate juice on insulin secretion and sensitivity in patients with obesity. Ann Nutr Metab 58(3):220-223. https://doi.org/10.1159/000330116

58. Guo C, Wei J, Yang J, Xu J, Pang W, Jiang Y (2008) Pomegranate juice is potentially better than apple juice in improving antioxidant function in elderly subjects. Nutr Res 28(2):72-77. https:// doi.org/10.1016/j.nutres.2007.12.001

59. Hollis JH, Houchins JA, Blumberg JB, Mattes RD (2009) Effects of concord grape juice on appetite, diet, body weight, lipid profile, and antioxidant status of adults. J Am Coll Nutr 28(5):574582. https://doi.org/10.1080/07315724.2009.10719789

60. Karlsen A, Paur I, Bøhn SK, Sakhi AK, Borge GI, Serafini M, Erlund I, Laake P, Tonstad S, Blomhoff R (2010) Bilberry juice modulates plasma concentration of NF-kappaB related inflammatory markers in subjects at increased risk of CVD. Eur J Nutr 49(6):345-355. https://doi.org/10.1007/s00394-010-0092-0

61. Khan F, Ray S, Craigie AM, Kennedy G, Hill A, Barton KL, Broughton J, Belch JJ (2014) Lowering of oxidative stress improves endothelial function in healthy subjects with habitually low intake of fruit and vegetables: a randomized controlled trial of antioxidant- and polyphenol-rich blackcurrant juice. Free Radic Biol Med 72:232-237. https://doi.org/10.1016/j. freeradbiomed.2014.04.006

62. Kojadinovic MI, Arsic AC, Debeljak-Martacic JD, KonicRistic AI, Kardum ND, Popovic TB, Glibetic MD (2017) Consumption of pomegranate juice decreases blood lipid peroxidation and levels of arachidonic acid in women with metabolic syndrome. J Sci Food Agric 97(6):1798-1804. https:// doi.org/10.1002/jsfa.7977

63. Krikorian R, Boespflug EL, Fleck DE, Stein AL, Wightman JD, Shidler MD, Sadat-Hossieny S (2012) Concord grape juice supplementation and neurocognitive function in human aging. J Agric Food Chem 60(23):5736-5742. https://doi.org/10.1021/ jf300277g

64. Loo BM, Erlund I, Koli R, Puukka P, Hellström J, Wähälä K, Mattila P, Jula A (2016) Consumption of chokeberry (Aronia mitschurinii) products modestly lowered blood pressure and reduced low-grade inflammation in patients with mildly elevated blood pressure. Nutr Res 36(11):1222-1230. https://doi. org/10.1016/j.nutres.2016.09.005

65. Lynn A, Hamadeh H, Leung WC, Russell JM, Barker ME (2012) Effects of pomegranate juice supplementation on pulse wave velocity and blood pressure in healthy young and middle-aged men and women. Plant Foods Hum Nutr 67(3):309-314. https:// doi.org/10.1007/s11130-012-0295-Z

66. Lynn A, Mathew S, Moore CT, Russell J, Robinson E, Soumpasi V, Barker ME (2014) Effect of a tart cherry juice supplement on arterial stiffness and inflammation in healthy adults: a randomised controlled trial. Plant Foods Hum Nutr 69(2):122-127. https://doi.org/10.1007/s11130-014-0409-x

67. Moazzen H, Alizadeh M (2017) Effects of pomegranate juice on cardiovascular risk factors in patients with metabolic syndrome: a double-blinded, randomized crossover controlled trial. Plant Foods Hum Nutr 72(2):126-133. https://doi.org/10.1007/s1113 0-017-0605-6

68. Morand C, Dubray C, Milenkovic D, Lioger D, Martin JF, Scalbert A, Mazur A (2011) Hesperidin contributes to the vascular protective effects of orange juice: a randomized crossover study in healthy volunteers. Am J Clin Nutr 93(1):73-80. https://doi. org/10.3945/ajen.110.004945 
69. Neto MM, da Silva TF, de Lima FF, Siqueira TMQ, Toscano LT, de Moura SKMSF, Silva AS (2017) Whole red grape juice reduces blood pressure at rest and increases post-exercise hypotension. J Am Coll Nutr 36(7):533-540. https://doi. org/10.1080/07315724.2017.1331385

70. Novotny JA, Baer DJ, Khoo C, Gebauer SK, Charron CS (2015) Cranberry juice consumption lowers markers of cardiometabolic risk, including blood pressure and circulating C-reactive protein, triglyceride, and glucose concentrations in adults. J Nutr 145(6):1185-1193. https://doi.org/10.3945/jn.114.203190

71. Paquette M, Medina Larqué AS, Weisnagel SJ, Desjardins Y, Marois J, Pilon G, Dudonné S, Marette A, Jacques H (2017) Strawberry and cranberry polyphenols improve insulin sensitivity in insulin-resistant, non-diabetic adults: a parallel, double-blind, controlled and randomised clinical trial. Br J Nutr 117(4):519-531. https://doi.org/10.1017/S0007114517000393

72. Park YK, Lee SH, Park E, Kim JS, Kang MH (2009) Changes in antioxidant status, blood pressure, and lymphocyte DNA damage from grape juice supplementation. Ann N Y Acad Sci 1171:385390. https://doi.org/10.1111/j.1749-6632.2009.04907.x

73. Ruel G, Lapointe A, Pomerleau S, Couture P, Lemieux S, Lamarche B, Couillard C (2013) Evidence that cranberry juice may improve augmentation index in overweight men. Nutr Res 33(1):41-49. https://doi.org/10.1016/j.nutres.2012.11.002

74. Shidfar F, Heydari I, Hajimiresmaiel SJ, Hosseini S, Shidfar S, Amiri F (2012) The effects of cranberry juice on serum glucose, apoB, apoA-I, Lp(a), and Paraoxonase- 1 activity in type 2 diabetic male patients. J Res Med Sci 17(4):355-360

75. Siasos G, Tousoulis D, Kokkou E, Oikonomou E, Kollia ME, Verveniotis A, Gouliopoulos N, Zisimos K, Plastiras A, Maniatis K, Stefanadis C (2014) Favorable effects of concord grape juice on endothelial function and arterial stiffness in healthy smokers. Am J Hypertens 27(1):38-45. https://doi.org/10.1093/ajh/hpt17 6

76. Silver HJ, Dietrich MS, Niswender KD (2011) Effects of grapefruit, grapefruit juice and water preloads on energy balance, weight loss, body composition, and cardiometabolic risk in free-living obese adults. Nutr Metab (Lond) 8(1):8. https://doi. org/10.1186/1743-7075-8-8

77. Simpson EJ, Mendis B, Macdonald IA (2016) Orange juice consumption and its effect on blood lipid profile and indices of the metabolic syndrome; a randomised, controlled trial in an at-risk population. Food Funct 7(4):1884-1891. https://doi.org/10.1039/ c6fo00039h

78. Sohrab G, Nasrollahzadeh J, Zand H, Amiri Z, Tohidi M, Kimiagar M (2014) Effects of pomegranate juice consumption on inflammatory markers in patients with type 2 diabetes: a randomized, placebo-controlled trial. J Res Med Sci 19(3):215-220

79. Sohrab G, Angoorani P, Tohidi M, Tabibi H, Kimiagar M, Nasrollahzadeh J (2015) Pomegranate (Punicagranatum) juice decreases lipid peroxidation, but has no effect on plasma advanced glycated end-products in adults with type 2 diabetes: a randomized double-blind clinical trial. Food Nutr Res 59:28551. https://doi.org/10.3402/fnr.v59.28551

80. Sumner MD, Elliott-Eller M, Weidner G, Daubenmier JJ, Chew MH, Marlin R, Raisin CJ, Ornish D (2005) Effects of pomegranate juice consumption on myocardial perfusion in patients with coronary heart disease. Am J Cardiol 96(6):810-814. https://doi. org/10.1016/j.amjcard.2005.05.026

81. Tsang C, Smail NF, Almoosawi S, Davidson I, Al-Dujaili EA (2012) Intake of polyphenol-rich pomegranate pure juice influences urinary glucocorticoids, blood pressure and homeostasis model assessment of insulin resistance in human volunteers. J Nutr Sci 1:e9. https://doi.org/10.1017/jns.2012.10

82. Aune D, Giovannucci E, Boffetta P, Fadnes LT, Keum N, Norat T, Greenwood DC, Riboli E, Vatten LJ, Tonstad S (2017) Fruit and vegetable intake and the risk of cardiovascular disease, total cancer and all-cause mortality-a systematic review and doseresponse meta-analysis of prospective studies. Int J Epidemiol 46(3):1029-1056. https://doi.org/10.1093/ije/dyw319

83. Khan T, Chiavaroli L, Zurbau A, Sievenpiper L, J, (2019) A lack of consideration of a dose-response relationship can lead to erroneous conclusions regarding $100 \%$ fruit juice and the risk of cardiometabolic disease. Eur J Clin Nutr 73(12):1556-1560

84. Tousoulis D, Koutsogiannis M, Papageorgiou N, Siasos G, Antoniades C, Tsiamis E, Stefanadis C (2010) Endothelial dysfunction: potential clinical implications. Minerva Med 101:271-284

85. D'Elia L, Strazzullo P (2019) Sodium and Potassium. In: Mancia G, Grassi G, Tsioufis K, Dominiczak A, Agabiti Rosei E (Eds.) Manual of Hypertension of the European Society of Hypertension, Third Edition. 2019. CRC Press. https://doi. org/10.1201/9780429199189

86. D'Elia L, Barba G, Cappuccio FP, Strazzullo P (2011) Potassium intake, stroke, and cardiovascular disease. A meta-analysis of prospective studies. J Am Coll Cardiol 57:1210-1219

87. D'Elia L, Iannotta C, Sabino P, Ippolito R (2014) Potassium rich-diet and risk of stroke: updated meta-analysis. NMCD 24:585-587

88. Castro H, Raij L (2013) Potassium in hypertension and cardiovascular disease. Semin Nephrol 33(3):277-289

89. He FJ, Marciniak M, Carney C, Markandu ND, Anand V, Fraser WD, Dalton RN, Kaski JC, MacGregor GA (2010) Effects of potassium chloride and potassium bicarbonate on endothelial function, cardiovascular risk factors, and bone turnover in mild hypertensives. Hypertension 55(3):681-688

90. Tang X, Wu B, Luo Y, Peng L, Chen Y, Zhu J, Peng C, Li S, Liu J (2017) Effect of potassium supplementation on vascular function: a meta-analysis of randomized controlled trials. Int J Cardiol 228:225-232

91. Freedman JE, Parker C 3rd, Li L, Perlman JA, Frei B, Ivanov V, Deak LR, Iafrati MD, Folts JD (2001) Select flavonoids and whole juice from purple grapes inhibit platelet function and enhance nitric oxide release. Circulation 103:2792-2798

92. Rizza S, Muniyappa R, Iantorno M, Kim JA, Chen H, Pullikotil P, Senese N, Tesauro M, Lauro D, Cardillo C, Quon MJ (2011) Citrus polyphenol hesperidin stimulates production of nitric oxide in endothelial cells while improving endothelial function and reducing inflammatory markers in patients with metabolic syndrome. J Clin Endocrinol Metab 96:782-792

93. Andriambeloson E, Stoclet JC, Andriantsitohaina R (1999) Mechanism of endothelial nitric oxide-dependent vasorelaxation induced by wine polyphenols in rat thoracic aorta. J Cardiovasc Pharmacol 33:248-254

94. Choi EM, Lee YS (2010) Effects of hesperetin on the production of inflammatory mediators in IL-1beta treated human synovial cells. Cell Immunol 264:1-3

95. Homayouni F, Haidari F, Hedayati M, Zakerkish M, Ahmadi K (2017) Hesperidin supplementation alleviates oxidative DNA damage and lipid peroxidation in type 2 diabetes: a randomized double-blind placebo-controlled clinical trial. Phytother Res 31(10):1539-1545. https://doi.org/10.1002/ptr.5881

96. Elavarasan J, Velusamy P, Ganesan T, Ramakrishnan SK, Rajasekaran D, Periandavan K (2012) Hesperidin-mediated expression of Nrf2 and upregulation of antioxidant status in senescent rat heart. J Pharm Pharmacol 64:1472-1482

97. Johnston CS, Dancho C, Strong G (2003) Orange juice ingestion and supplemental vitamin $\mathrm{C}$ are equally effective at reducing plasma lipid peroxidation in healthy adult women. $\mathrm{J}$ Am Coll Nutr 22:519-523

98. Cha JY, Cho YS, Kim I, Anno T, Rahman SM, Yanagita T (2001) Effect of hesperetin, a citrus flavonoid, on the liver triacylglycerol content and phosphatidate phosphohydrolase 
activity in orotic acid-fed rats. Plant Foods Hum Nutr 56:349-358

99. Lee RY, Jung JH, Kim HS (2011) Hesperidin partially restores impaired immune and nutritional function in irradiated mice. $\mathrm{J}$ Med Food 14:475-482

100. Kim SW, Kim CE, Kim MH (2011) Flavonoids inhibit high glucose-induced up-regulation of ICAM-1 via the p38 MAPK pathway in human vein endothelial cells. Biochem Biophys Res Commun 415:602-607

101. Osganian SK, Stampfer MJ, Rimm E, Spiegelman D, Manson JE, Willett WC (2003) Dietary carotenoids and risk of coronary artery disease in women. Am J Clin Nutr 77(6):1390-1399

102. Aschoff JK, Rolke CL, Breusing N, Bosy-Westphal A, Högel J, Carle R, Schweiggert RM (2015) Bioavailability of $\beta$-cryptoxanthin is greater from pasteurized orange juice than from fresh oranges - a randomized cross-over study. Mol Nutr Food Res 59(10):1896-1904

103. Mortensen A, Skibsted LH, Truscott TG (2001) The interaction of dietary carotenoids with radical species. Arch Biochem Biophys 385(1):13-19

104. Achan V, Tran CTL, Arrigoni F, Guy St J, Whitley JM, Leiper PV (2002) All-transretinoic acid increases nitric oxide synthesis by endothelial cells - a role for the induction of dimethylarginine dimethylaminohydrolase. Circ Res 90:764-769

105. Fontana L, Mcneill KL, Ritter JM, Chowienczyk PJ (1999) Effects of vitamin $\mathrm{C}$ and of a cell permeable superoxide dismutase mimetic on acute lipoprotein induced endothelial dysfunction in rabbit aortic rings. Br J Pharmacol 126:730-734

106. Heller R, Munscher-Paulig F, Grabner R, Till U (1999) L-ascorbic acid potentiates nitric oxide synthesis in endothelial cells. J Biol Chem 274:8254-8260

107. Wu DY, Koga T, Martin KR, Meydani M (1999) Effect of vitamin $\mathrm{E}$ on human aortic endothelial cell production of chemokines and adhesion to monocytes. Atherosclerosis 147:297-307

108. Faruqi R, Delamotte C, Dicorleto PE (1994) Alphatocopherol inhibits agonist-induced monocytic cell adhesion to cultured human endothelial cells. J Clin Invest 94:592-600

109. Wilmink HW, Stroes ESG, Erkelens WD, Gerritsen WB, Wever R, Banga JD, Rabelink TJ (2000) Influence of folic acid on postprandial endothelial dysfunction. Arterioscler Thromb Vasc Biol 20:185-188

110. Malinow MR, Bostom AG, Krauss RM (1999) Homocyst(e)ine, diet, and cardiovascular diseases-a statement for healthcare professionals from the Nutrition Committee American Heart Association. Circulation 99:178-182

111. Hayes DP (2007) Nutritional hormesis. Eur J Clin Nutr 61:147-159

112. Garduño-Alanís A, Malyutina S, Pajak A, Stepaniak U, Kubinova R, Denisova D, Pikhart H, Peasey A, Bobak M, Stefler D (2019) Association between soft drink, fruit juice consumption and obesity in Eastern Europe: cross-sectional and longitudinal analysis of the HAPIEE study. J Hum Nutr Diet. https://doi.org/10.1111/ jhn. 12696

113. Auerbach BJ, Littman AJ, Krieger J, Young BA, Larson J, Tinker L, Neuhouser ML (2018) Association of 100\% fruit juice consumption and 3-year weight change among postmenopausal women in the in the Women's Health Initiative. Prev Med 109:8-10. https://doi.org/10.1016/j.ypmed.2018.01.004

114. Auerbach BJ, Wolf FM, Hikida A, Vallila-Buchman P, Littman A, Thompson D, Louden D, Taber DR, Krieger J (2017) Fruit juice and change in BMI: a meta-analysis. Pediatrics 139(4):e20162454. https://doi.org/10.1542/peds.2016-2454

115. Choi HS (2006) Lipolytic effects of citrus peel oils and their components. J Agric Food Chem 54:3254-3258

116. Kang SI, Shin HS, Kim HM, Hong YS, Yoon SA, Kang SW, Kim JH, Kim MH, Ko HC, Kim SJ (2012) Immature Citrus sunki peel extract exhibits antiobesity effects by beta-oxidation and lipolysis in high-fat diet-induced obese mice. Biol Pharm Bull 35:223-230

117. Takayanagi K (2011) Prevention of adiposity by the oral administration of beta-cryptoxanthin. Front Neurol 2:67

118. Lima ACD, Cecatti C, Fidélix MP, Adorno MAT, Sakamoto IK, Cesar TB, Sivieri K (2019) Effect of daily consumption of orange juice on the levels of blood glucose, lipids, and gut microbiota metabolites: controlled clinical trials. J Med Food 22(2):202-210

119. Xi B, Li S, Liu Z, Tian H, Yin X, Huai P, Tang W, Zhou D, Steffen LM (2014) Intake of fruit juice and incidence of type 2 diabetes: a systematic review and meta- analysis. PLoS ONE 9:e93471

120. Imamura F, O'Connor L, Ye Z, Mursu J, Hayashino Y, Bhupathiraju SN, Forouhi NG (2015) Consumption of sugar sweetened beverages, artificially sweetened beverages, and fruit juice and incidence of type 2 diabetes: systematic review, meta-analysis, and estimation of population attributable fraction. BMJ $351: \mathrm{h} 3576$

121. Ruxton CH, Gardner EJ, Walker D (2006) Can pure fruit and vegetable juices protect against cancer and cardiovascular disease too? A review of the evidence. Int J Food Sci Nutr 57(3-4):249-272

122. Hyson DA (2015) A review and critical analysis of the scientific literature related to $100 \%$ fruit juice and human health. Adv Nutr 6:37-51

123. Aptekmann NP, Cesar TB (2013) Long-term orange juice consumption is associated with low LDL-cholesterol and apolipoprotein B in normal and moderately hypercholesterolemic subjects. Lipids Health Dis 12:119. https://doi. org/10.1186/1476-511X-12-119

124. Aviram M, Rosenblat M, Gaitini D, Nitecki S, Hoffman A, Dornfeld L, Volkova N, Presser D, Attias J, Liker H, Hayek T (2004) Pomegranate juice consumption for 3 years by patients with carotid artery stenosis reduces common carotid intimamedia thickness, blood pressure and LDL oxidation. Clin Nutr 23:423-433

125. Davidson MH, Maki KC, Dicklin MR, Feinstein SB, Witchger M, Bell M, McGuire DK, Provost JC, Liker H, Aviram M (2009) Effects of consumption of pomegranate juice on carotid intimamedia thickness in men and women at moderate risk for coronary heart disease. Am J Cardiol 104:936-942

126. Timmis A, Townsend N, Gale C, Grobbee R, Maniadakis N, Flather M, Wilkins E, Wright L, Vos R, Bax J, Blum M, Pinto F, Vardas P, ESC Scientific Document Group (2018) European society of cardiology: cardiovascular disease statistics 2017. Eur Heart J 39(7):508-579. https://doi.org/10.1093/eurheartj/ehx628

127. Lewington S, Clarke R, Qizilbash N, Peto R, Collins R (2002) Age-specific relevance of usual blood pressure to vascular mortality: a meta-analysis of individual data for one million adults in 61 prospective studies. Lancet 360:1903-1913

128. Department of Health and Human Services and US Department of Agriculture (2015) 2015-2020 Dietary Guidelines for Americans, 8th ed.Washington, US Government Printing Office

129. The American Heart Association. Healthy Eating-Suggested Servings from Each Food Group. https://www.heart.org/HEART ORG/HealthyLiving/HealthyEating/HealthyDietGoals/Sugge sted-Servings-from-Each-Food-Group_UCM_318186_Artic le.jsp\#. WAYU8uCLRm9. Accessed 2 Jan 2020

130. Buttriss JL (2016) The Eatwell Guide refreshed. Nutr Bull 41:135-141

131. Health Council of the Netherlands (2015) Dutch Dietary Guidelines 2015. Publication no. 2015/24E. The Hague: Health Council of the Netherlands. www.healthcouncil.nl. Accessed 2 Jan 2020 
132. Società Italiana di Nutrizione Umana-SINU (2014). Livelli di Assunzione di Riferimento di Nutrienti ed energia per la popolazione italiana-IV Revisione. SICS Ed, Rome

133. Ravn-Haren G, Dragsted LO, Buch-Andersen T, Jensen EN, Jensen RI, Németh-Balogh M, Paulovicsová B, Bergström A,
Wilcks A, Licht TR, Markowski J, Bügel S (2013) Intake of whole apples or clear apple juice has contrasting effects on plasma lipids in healthy volunteers. Eur J Nutr 52(8):1875-1889. https://doi.org/10.1007/s00394-012-0489-z

\section{Affiliations}

\section{Lanfranco D'Elia ${ }^{1}$ (D) Monica Dinu ${ }^{2} \cdot$ Francesco Sofi $^{2} \cdot$ Massimo Volpe $^{3,4} \cdot$ Pasquale Strazzullo ${ }^{1}$ on behalf of The SINU Working Group, Endorsed by SIPREC}

1 Department of Clinical Medicine and Surgery, ESH Excellence Centre of Hypertension, "Federico II" University of Naples Medical School, Via S. Pansini, 5. 80131, Naples, Italy

2 Department of Experimental and Clinical Medicine, University of Florence, Florence, Italy
3 Department of Clinical and Molecular Medicine, School of Medicine and Psychology, Sapienza University of Rome, Rome, Italy

4 IRCCS Neuromed, Pozzilli, IS, Italy 